\begin{tabular}{|c|c|c|c|c|c|}
\hline MUNIBE Antropologia-Arkeologia & $n^{\circ} 66$ & $291-308$ & DONOSTIA & 2015 & ISSN 1132-2217 • eISSN 2172-4555 \\
\hline
\end{tabular}

\title{
Artefactos e instrumentos de piedra en un espacio de almacenamiento colectivo. El caso de El Cenobio de Valerón (Gran Canaria, España)
}

\author{
Lithic implements in a communal granary. \\ The example of Cenobio de Valerón (Gran Canaria, Spain)
}

PALABRAS CLAVES: Gran Canaria, periodo preeuropeo, granero, materiales de molturación, industria lítica tallada. GAKO-HITZAK: Kanaria Handia, aldi aurreeuroparra, bihitegia, ehotze-materialak, landutako industria litikoa. KEY WORDS: Gran Canaria, pre-european period, granary, grinding stone tools, knapped lithic industry.

Yurena NARANJO-MAYOR(1) \& Amelia RODRÍGUEZ-RODRÍGUEZ(2)

\section{RESUMEN}

Los graneros comunales constituyen una peculiaridad del registro arqueológico preeuropeo de Gran Canaria, aunque sean más conocidos en el Norte de África. El Cenobio de Valerón presenta singularidades que lo sitúan como uno de los monumentos más espectaculares de la isla, sobre todo por su envergadura y la variedad de interpretaciones que se le han dado. A pesar de los expolios sufridos durante más de 300 años, todavía se conservan elementos que aportan información sobre la naturaleza de las materias almacenadas, la configuración de los espacios o las actividades allí desarrolladas. Aquí se presenta, el conjunto de artefactos líticos, vinculados con el procesado de materias vegetales o el acondicionamiento de los silos. Su estudio morfotécnico y funcional, es el primero realizado en un contexto de almacenamiento, lo que permitirá comprender mejor las funciones de estos recintos en las relaciones sociales de producción de los antiguos canarios.

\section{LABURPENA}

Bihitegi komunalak Kanaria Handietako erregistro arkeologiko aurreeuroparraren berezitasuna dira, Afrika iparraldean ezagunagoak izan arren. Valeróngo zenobioak berezitasun handiak ditu; hori dela eta, uharteko monumentu ikusgarrienetako bat da, batez ere duen neurriagatik eta eman zaizkion interpretazio ugariengatik. 300 urte baino gehiagoz espoliazioak jasan arren, oraindik ere gordetako materien izaerari, espazioen konfigurazioari edo han garatutako jarduerei buruzko informazioa ematen duten elementuak gordetzen ditu. Hemen aurkezten da landare-materien prozesatzearekin eta siloen egokitzapenarekin lotutako gailu litikoen multzoa. Haien azterketa morfotekniko eta funtzionala da biltegiratze arloan egindako lehenengoa, eta horrek ahalbidetuko du garai bateko kanariarren ekoizpeneko harreman sozialetan esparru horiek zituzten funtzioak hobeto ulertzea.

\section{ABSTRACT}

Communal granaries are a peculiarity of the archaeological record of the pre-European stage in Gran Canaria Island, although they are more known in North Africa. Among them, the Cenobio of Valerón has singularities that raise it as one of the most spectacular archaeological sites of ancient canaries. Its monumentality and the variety of interpretations about its functionality have attracted scientifics and curious people for a long time. Despite the changes experienced during more than 300 years, there are elements that still give information about the commodities preserved there, the strategies of its construction and the variety of activities developed inside. We are presenting here the whole set of lithic artifacts related to the plant processing and in other tasks, such as the carving of silos. This morpho-technical and functional study is the first approach that takes into account these devices in a context of storage. So, we believe that it may help to better understand the nature and functions that granaries had in the social relations of production from the ancient canaries.

\section{1.- INTRODUCCIÓN Y OBJETIVOS}

El Cenobio de Valerón es uno de los vestigios de los antiguos canarios que fue reconocido como tal desde el S. XVII, debido a su tamaño y espectacularidad. Ha sido objeto de diversas intervenciones, entre las que destacan los trabajos realizados entre 1972 y 1973 , orientados al acon-

dicionamiento del yacimiento para su apertura al público En 1978 fue declarado Monumento Histórico Artístico. Durante los años 80 y 90 del siglo XX se llevaron a cabo varias acciones de mejora, auspiciadas por la Consejería de Cultura y Deporte del Gobierno de Canarias y el Cabildo de Gran Canaria.

(1) G.I. Tarha. Becaria FPI. Universidad de Las Palmas de Gran Canaria, yurena.nm@gmail.com (Malvavisco, 3, 2 D Las Palmas de Gran Canaria, Las Palmas)

(2) G.I. Tarha. Dpto. Ciencias Históricas, Universidad de Las Palmas de Gran Canaria. 
Sin embargo, sólo cuando se acometieron los trabajos de restauración fomentados por el Cabildo, a comienzos del siglo XXI, se dieron las condiciones para realizar su estudio integral (Barroso y Marrero, 2009). Nuestro grupo de investigación pretende contribuir en esa tarea, desde las distintas líneas de trabajo que desarrollamos. Aunque el sitio ha sido foco de expolios por parte de eruditos y aficionados a la arqueología, a lo que hay que sumar los trabajos realizados en el siglo XX con métodos menos apropiados que los actuales (Jiménez, 1944), este yacimiento siguió atesorando interesantes evidencias que van a permitir comprender el papel que desempeñaban estos emplazamientos en las relaciones sociales de producción de los antiguos canarios.

Uno de los primeros estudios que hemos desarrollado concierne a la industria lítica. Así, nos hemos marcado unos objetivos que contribuyan a elaborar una propuesta sobre las actividades desarrolladas en estos recintos, partiendo de este estudio. Con ello se podrá ir completando la perspectiva que se tiene de los graneros, para los que estamos conociendo aspectos ligados a los procesos de almacenamiento de vegetales, así como su cronología (Morales et al., 2014; Morales y Rodríguez, 2014) (Tabla I).Por tanto nos hemos propuesto los siguientes objetivos específicos:

1. Caracterizar los diversos artefactos líticos presentes en el yacimiento y clasificarlos atendiendo a sus características morfológicas, tipométricas y tecnológicas.

2. Identificar las actividades desempeñadas en este lugar, mediante el estudio funcional del material, con el fin de integrarlas en la interpretación de estos espacios.

3. Contribuir a la compresión de los procesos postdeposicionales que han afectado al sitio para mejorar la interpretación de sus evidencias.

\section{2.- EL CENOBIO DE VALERÓN}

\subsection{Contexto geográfico e historiográfico}

El Cenobio de Valerón está localizado en el T.M. de Santa María de Guía en el norte de Gran Canaria a 263 m.s.n.m. (UTM 3112764/3112741) (Figura 1). Geológicamente se trata de un gran arco natural de $20 \mathrm{~m}$ de altura por $27 \mathrm{~m}$ de ancho, situado en un acantilado del margen izquierdo del Barranco de Silva, que surge por el desmantelamiento del cono volcánico de Montaña del Gallego (Barroso y Marrero, 2009).En él se horadaron cerca de 300 cavidades, interpretadas como silos, gracias a las características de la toba o lapilli -ceniza volcánica compactada- que actúa como soporte. Este lapilli procede de la erupción del volcán de Montaña Clavijo (Mangas et al., 2006) y posee unas condiciones idóneas para labrar estructuras negativas porque no es muy duro y puede ser trabajado con artefactos líticos.

La visibilidad del enclave y los materiales que todavía podían observarse cuando se realizaron las primeras "excavaciones" han permitido que dispongamos de descripciones del S. XIX. No obstante la referencia a conjuntos con características similares, que parecen estar describiendo este lugar, se recoge en algunas fuentes etnohistóricas (Morales, 1978).

Un ejemplo es la crónica del S. XV de Pedro Gómez Escudero (Baucells, 2004), con la siguiente anotación:

[...] tenían pósitos onde encerraban cebada y cosa de comer, y era de los frutos como diezmo que daban en aquél depósito para los años faltos y hacer repartimiento de limosnas: Tenían silos en los riscos y se conservaba el grano muchos años sin dañarse [...]

\section{Gómez Escudero [1484] (1936), 82}

Ya en el siglo XVII, en la Historia Regional de Pedro Agustín del Castillo, aparece la primera mención al yacimiento:

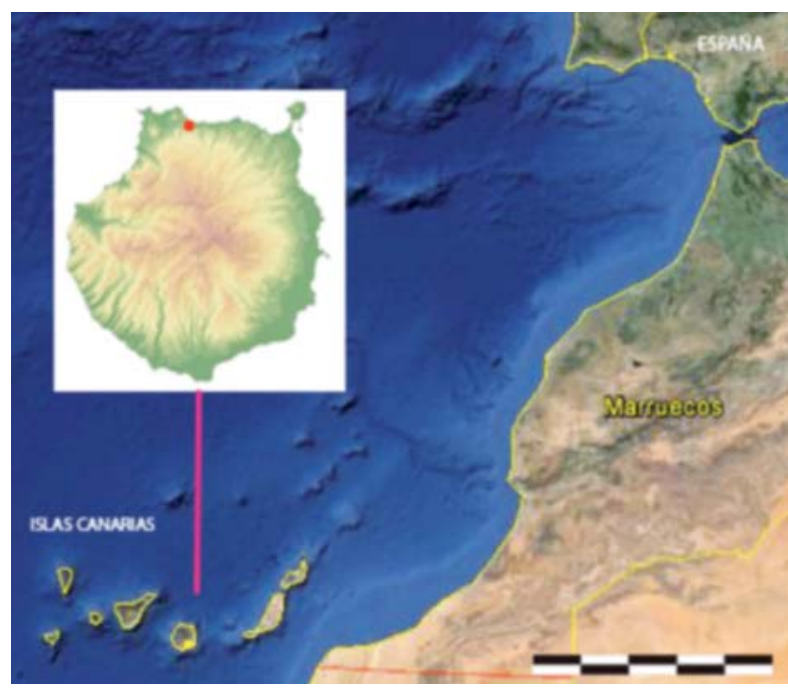

Fig. 1. Mapa de situación de El Cenobio de Valerón. Escala 1:100000 / Location map from Cenobio of Valerón. Scae1:100.000.

\begin{tabular}{|c|c|c|c|c|}
\hline REFERENCIA & MUESTRA & TIPO & CONVENCIONAL & CALIBRADA 2 $\sigma$ \\
\hline Beta - 384697 & CV09Z10S15M2 & Raquis cebada desecado & $520+/-30 B P$ & $\begin{array}{l}\text { Cal AD } 1330 \text { to } 1340 \text { (Cal BP } 620 \text { to } 610) \text { and } \\
\text { Cal } A D 1395 \text { to } 1440 \text { (Cal BP } 555 \text { to 510) }\end{array}$ \\
\hline Beta - 390473 & CV09Z8S38M4 & Semilla de cebada carbonizada & $600+/-30 B P$ & Cal AD 1295 to 1410 (Cal BP 655 to 540) \\
\hline Beta - 384696 & CV09Z10S11M1 & Semilla de cebada carbonizada & $670+/-30 B P$ & $\begin{array}{c}\text { Cal AD } 1275 \text { to } 1315 \text { (Cal BP } 675 \text { to } 635) \text { and } \\
\text { Cal } A D 1355 \text { to } 1390 \text { (Cal BP } 595 \text { to 560) }\end{array}$ \\
\hline Beta - 390474 & CV09Z8S10M5 & Semilla de cebada carbonizada & $780+/-30 B P$ & Cal $A D 1215$ to 1280 (Cal BP 735 to 670$)$ \\
\hline Beta - 384698 & CV09Z15S1M3 & Semillas de higo desecadas & $890+/-30 B P$ & Cal AD 1040 to 1220 (Cal BP 910 to 730$)$ \\
\hline
\end{tabular}

Tabla 1: Dataciones Cenobio de Valerón / Radiocarbonic dates from Cenobio de Valerón. 
[...] Barranco que llaman de Valerón [...] en un risco se hizo sin herramientas templadas, porque no las conocieron... (sino lascas de pedernales, que fijaban en unos palos como hachas y azuelas [...]a la entrada, corría un largo cañón, o crujía que corría hacia dentro, y de un lado y otro con grande igualdad, y correspondencia mucho número de celdas, o aposentos, unos sobre de otros con sus ventanillas $[\ldots]$

Pedro Agustín del Castillo [1737] (1848), 56

En el S. XIX Agustín Millares Torres (Millares, 1880), narra su visita al yacimiento. El autor detalla el colapso parcial de la techumbre y paredes laterales, verificando además el expolio que sufría el sitio, aludiendo a que no aparecía nada en superficie, pese a que los vecinos aseguraban haber visto cerámica y huesos tiempo atrás. Asimismo interpreta los silos como dormitorios haciéndose eco de una de las versiones aceptadas en aquella época, que consideraba el lugar como morada de cenobitas. Esta idea se recoge en otras obras, como la de José Batllori y Lorenzo, que lo relaciona con el ritual de las harimaguadas relatado en varias fuentes etnohistóricas (Batllori, 1901).

Ya en el S.XX, Sebastián Jiménez Sánchez, Comisario de Excavaciones de la Provincia de Las Palmas comenzó los primeros trabajos sobre el sitio, con la ayuda de los arqueólogos Julio Martínez Santa-Olalla y George Marcy (Jiménez Sánchez, 1943, 1944), que definieron el enclave como granero. Esta interpretación ha sido la predominante desde entonces, aunque se introdujeron nuevos elementos a la discusión, como la forma más correcta de denominar el lugar. Así, Dominik Josef Wölfel (1954: 84), aun destacando el uso del Cenobio como almacén, criticó el empleo del término Agadir utilizado por Julio Martínez Santa Olalla, ya que consideraba que esta terminología era incorrecta, puesto que en el Norte de África designaba un castillo o fortificación.

Los estudios más recientes sobre los sistemas de almacenamiento de Gran Canaria, asocian esta tipología de yacimientos a graneros. De forma general se distingue entre los colectivos, como el Cenobio de Valerón, y los de carácter individual, mucho más pequeños y situados en espacios domésticos. Se incide en conocer los métodos para preservar el grano, la capacidad y el control ambiental de los silos, para así comprender el papel de estos lugares en la estructura socioeconómica de los antiguos canarios (Onrubia, 1989, 2003; Morales, 2010). Por otra parte, la ubicación y el difícil acceso al Cenobio, favorece su identificación como granero fortificado, similar a los norteafricanos (Onrubia, 1986, Delaigne et al., 2006).

Por último, hay que mencionar su interpretación como lugar de enterramiento, pues se constata la presencia de restos humanos (Hernández, 1944). A mediados de los años 90 del S. XX, cuando se presentaron otras propuestas sobre el origen del poblamiento del Archipiélago, el yacimiento fue descrito como un monumento de filiación fenicio-púnica, interpretando las oquedades como estructuras funerarias (hipogeos) con paralelos en las colonias fenicias de Occidente (Atoche 1993, Atoche y Martín, 1999, Atoche y Ramírez, 2001, Balbín et al., 1995).

\section{3.- MATERIAL Y MÉTODO}

El material lítico analizado procede fundamentalmente de la intervención llevada a cabo en el año 2009 por la empresa Arqueocanaria S.L. (Barroso y Marrero, 2009). Se actuó de forma integral en todos los silos y la zona de la visera, con unas operaciones de limpieza y documentación que implicaron la recogida de la totalidad de materiales arqueológicos de cada estructura. Cuando se conservaba sedimento se tomaron muestras para el estudio arqueobotánico. Además se integraron los materiales depositados en El Museo Canario, procedentes de la etapa de la Comisaría de Excavaciones Arqueológicas (Ramírez, 2000). En este caso no se dispone de información precisa sobre la ubicación de las evidencias conservadas.

La envergadura del sitio, el elevado número de silos y su distribución en pisos, articulados en pasillos o en torno a cámaras de mayores dimensiones, hace difícil establecer una buena descripción de los sectores que lo integran (Figura 2). En este trabajo se va a utilizar la sectorización realizada por Arqueocanarias S. L. en 1994, que agrupa los silos en 15 zonas, más el área de visera (Figura 3).

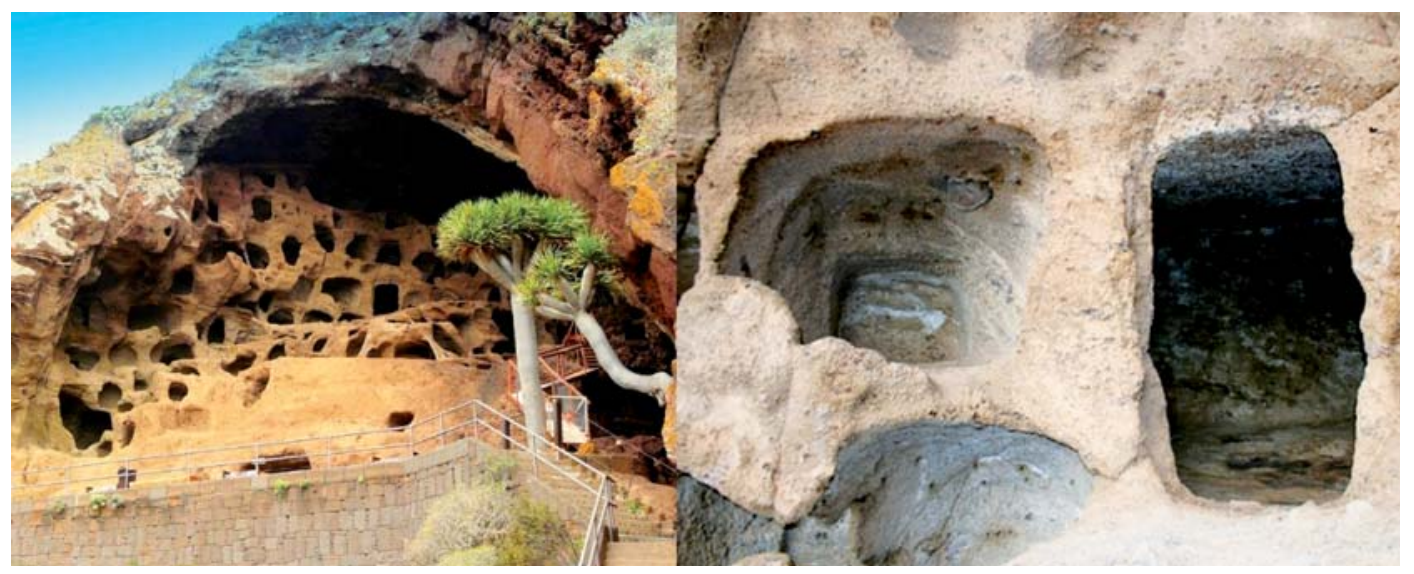

Fig. 2. Cenobio de Valerón. Detalle de dos de los silos (derecha). / Cenobio of Valerón. Detail of two negative structures (right). 


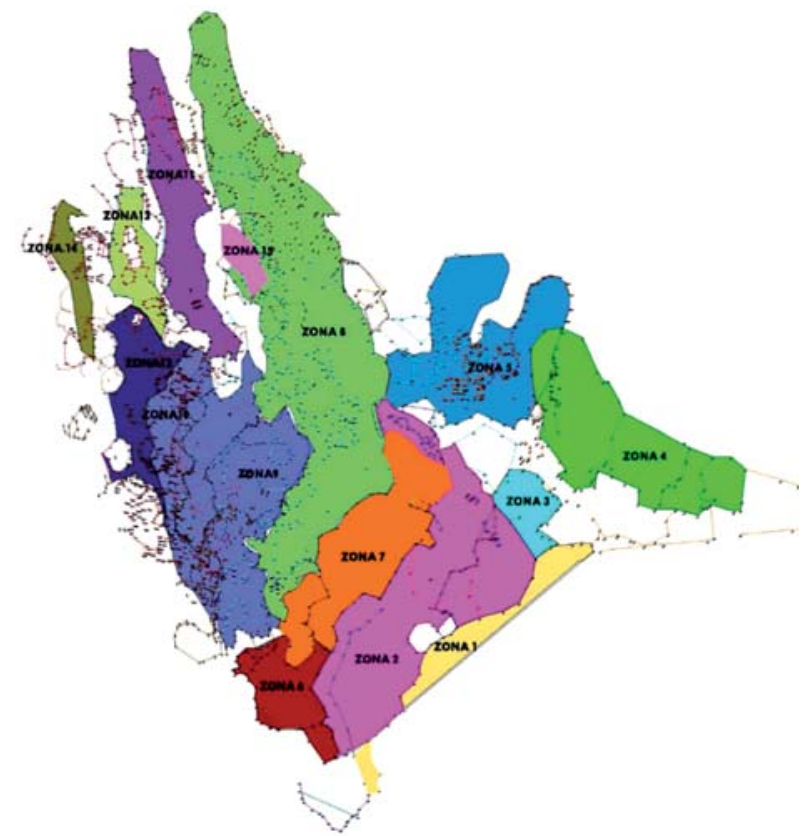

Fig. 3. Sectorización del Cenobio de Valerón (Arqueocanarias, 1994) / Zoning of Cenobio of Valerón.

Los resultados del análisis morfotécnico y funcional de los artefactos se presentan en conjunto, sin atender a su localización.

Desde el punto de vista metodológico, se ha procedido al estudio integral de los artefactos líticos, independientemente de las técnicas y métodos empleados en su manufactura o modo de uso. Se ha recurrido a propuestas formuladas previamente para el análisis morfotécnico de los conjuntos líticos del Archipiélago (Galván et al., 1987; Galván y Hernández, 1996; Rodríguez, 1993, 2009; Rodríguez y Francisco, 2012; Naranjo 2013; Naranjo y Rodríguez, 2014). Con respecto al análisis funcional, todo el material se ha sometido a una observación microscópica, que ha permitido identificar huellas de uso y fabricación. Esta es la primera aproximación funcional a los materiales de molturación y las observaciones dependen de la comparación con los estigmas obtenidos en nuestro programa experimental. Para el material lítico tallado y algunos soportes no configurados intencionalmente contábamos con estudios previos y comparaciones con otros contextos (Adams et al., 2009; Alonso 1999; Anderson et al., 1993; Cuartero, 2014; Dubreuil, 2002; González e Ibáñez, 1994; Hamon, 2004; Hamon y Plisson, 2008, Keeley, 1980; Marreiros et al., 2015; Plisson, 1982 y 1983; Procopiu, 2001; Rodríguez-Rodríguez, 1993 a y b, 1998 a y b; 2009 a y b; Rodríguez-Rodríguez et al., 2006 a y b; Santallier et al., 2002).

En el análisis funcional se realizó en primer lugar una inspección de visu de los artefactos para advertir marcas de utilización o residuos. A continuación el estudio microscópico se desarrolló con una lupa binocular (Nikon SMZ1000), un microscopio metalográfico Nikon Labophot 2 y un microscopio invertido (Nikon MA100). Todos los aparatos están equipados con una cámara Nikon SD-Fi1 que permite registrar los estigmas. Se ha usado el software fotográfico Helicon Focus v. 4.62 para procesar las imágenes.

Estas técnicas se llevaron a cabo siempre que el tamaño de las piezas lo permitió, algo imposible en algunos materiales de molturación por su tamaño y su peso. Como alternativa se usaron moldes de acetato o silicona líquida, que registran parcialmente la superficie activa de los materiales (Dubreuil, 2004; Bofill, 2014).

En la Tabla II, se presenta el cómputo de las categorías que hemos considerado significativas para el análisis, organizadas en cuatro grupos. El primero lo conforma la industria lítica tallada. El segundo integra los materiales de molturación, con subgrupos que responden al modo en que han sido configurados e incluye algunos soportes no modificados intencionalmente (Naranjo y Rodríguez, 2014). El tercero engloba piezas no talladas (modificadas intencionalmente o no), que han sido asociadas con acciones distintas a la molturación, destacando los útiles alfareros. Por último, el cuarto grupo incluye las piezas definidas como material constructivo. Estos elementos aparecen subrepresentados en la tabla, ya que no se ha podido realizar el cómputo y ponderación de las piezas grandes de fractura plana, debido a su compleja manipulación.

\begin{tabular}{|l|c|c|c|c|}
\hline & \multicolumn{2}{|c|}{$\mathbf{N}^{\circ}$ piezas } & \multicolumn{2}{c|}{ Peso } \\
\hline Lítico tallado & 315 & $11,4 \%$ & $7167 \mathrm{gr}$ & $2,7 \%$ \\
\hline Molturación & 45 & $1,6 \%$ & $166665 \mathrm{gr}$ & $63 \%$ \\
\hline Otros útiles líticos & 44 & $1,6 \%$ & $24766 \mathrm{gr}$ & $9,3 \%$ \\
\hline Material constructivo & 2354 & $85,4 \%$ & $65634 \mathrm{gr}$ & $25 \%$ \\
\hline Total & 2757 & $100 \%$ & $264232 \mathrm{gr}$ & $100 \%$ \\
\hline
\end{tabular}

Tabla 2: Conjunto lítico de El Cenobio de Valerón / Lithic assemblage from Cenobio de Valerón.

\subsection{Grupo 1: Material lítico tallado}

El conjunto está integrado por 315 piezas talladas, 27 rocas volcánicas de grano grueso (RVGG) y 288 vidrios volcánicos (VV).

Entre las RVGG hay nueve soportes de basalto, 15 de fonolita, dos de tefrita y un indeterminado. No conocemos la procedencia de los basaltos, ya que escasea en las prospecciones realizadas, tanto en las cuencas de los barrancos como en las playas cercanas al sitio. Por el contrario, las fonolitas están presentes en el entorno del Cenobio de Valerón (Pérez, 2000) por lo que es fácil obtenerlas de bloques localizados en sus inmediaciones. Otro tanto puede decirse de las tefritas, que también se localizan, aunque en menor medida, en el entorno más cercano.

Las categorías de soportes documentadas son lascas, cantos, bloques e indeterminados (Tabla III). Entre las lascas se han contemplado las estrategias de explotación unidireccional (4) y centrípeta (3). Este bajo nivel de identificación se debe a la gran incidencia de piezas fracturadas y con escasez de aristas que permitan su clasificación. También existen cinco soportes con una reserva cortical superior al 50\%, que se consignan como corticales. Así, en ocho ocasiones las lascas están frag- 
mentadas por el talón, mientras que las plataformas de percusión más comunes son las lisas/planas. El resto de categorías es escaso, lo que constituye una constante entre los productos de lascado del Archipiélago (Galván et al., 1992; Galván y Hernández, 1996; Rodríguez, 1993, 2009). Sólo hay cuatro piezas retocadas: dos muescas y dos lascas con retoque simple continuo.

\begin{tabular}{|c|c|c|c|c|}
\hline \multirow{2}{*}{ MMPP } & & Lítico Tallado & \multicolumn{2}{|c|}{ Cantidad } \\
\hline & Soporte & Tipo & & \\
\hline & Indeterminado & pico & 1 & $3,7 \%$ \\
\cline { 2 - 5 } & Bloque & pico & 2 & $7,5 \%$ \\
\cline { 2 - 5 } & Canto & Unifacial & 1 & $3,7 \%$ \\
\hline & & Unidireccional (muesca) & 1 & $3,7 \%$ \\
\hline & & Centrípeta (muesca) & 1 & $3,7 \%$ \\
\hline RVGG & Lasca R & Cortical (ret continuo) & 1 & $3,7 \%$ \\
\hline & & Indeterminada (ret continuo) & 1 & $3,7 \%$ \\
\hline & & Unidireccional & 3 & $11,1 \%$ \\
\hline & & Centrípeta & 2 & $7,5 \%$ \\
\hline & Lasca & Cortical & 4 & 14,8 \\
\hline & & Indeterminada & 10 & $37,0 \%$ \\
\hline & & Total RVGG & 27 & $100 \%$ \\
\hline & & Unidireccional & 11 & $8,0 \%$ \\
\hline & & Cortical & 19 & $13,9 \%$ \\
\hline VV & Lasca & Bipolar & 94 & $68,6 \%$ \\
\hline & & Indeterminada & 13 & $9,5 \%$ \\
\hline & & Total VV & 137 & $100 \%$ \\
\hline
\end{tabular}

Tabla 3: Tipos de soporte RVGG y VV / Kind of supports RVGG and VV.

El segundo tipo de soporte en RVGG son los picos. Dos se elaboraron sobre bloques naturales con formas triangulares, que necesitaron un escaso nivel de configuración, ya que se preparó un único extremo activo (lo que corresponde a un tipo 3 de la clasificación morfológica de los picos propuesta en otro lugar (Rodríguez y Francisco, 2012). El trabajo se centró en crear ápices con fuertes bi- seles mediante extracciones bifaciales marginales. El tercero responde a una estrategia de configuración más elaborada, ya que presenta dos ápices activos del tipo picante triedro, es decir, con forma de pirámide de tres caras. La morfología general de la pieza es un triángulo invertido asimétrico, lo que corresponde a un tipo de pico 1(2) de la clasificación citada anteriormente. Se trata en todos los casos de piezas bastante grandes, con un peso que oscila entre los 308 y 986 gr (Figura 4).

Por último contamos con una pieza sobre canto, tallada unifacialmente y de gran formato, pues pesa $1220 \mathrm{gr}$. Su filo es de delineación convexa y presenta un ángulo de $45^{\circ}$ con huellas de uso muy desarrolladas.

Por lo que respecta a los $288 \mathrm{VV}$, se seleccionaron 137 para el estudio morfotécnico, considerando el resto como restos de talla (inferiores a 10mm). En este grupo también se han incluido 3 piezas de aspecto silíceo, ya que sus características geológicas y su modo de explotación son idénticos a los presentes en la obsidiana. Los VV se asocian de visu de forma mayoritaria con la obsidiana de origen traquítico procedente de las minas de Hogarzales y El Cedro (Rodríguez et al., 2007; Rodríguez, 2010). En solo ocho casos se determinó una procedencia desconocida. La obsidiana de las montañas de Hogarzales y El Cedro se caracteriza por su coloración gris-azulada, es opaca y su granulometría puede variar de muy fina a ligeramente rugosa. Tiene un córtex característico de su naturaleza ignimbrítica, muy rugoso y de coloraciones cenicientas o rojizas. Para corroborar si los criterios de visu son adecuados para identificarla, se ha realizado recientemente un análisis geoquímico mediante un aparato portátil de fluorescencia de Rayos X sobre una muestra de 8 piezas procedentes del granero. Los resultados se ajustaron a la clasificación macroscópica en todas las ocasiones. Se identificaron 7 piezas con el tipo Hogarzales. La octava tiene unas características distintas: su coloración es negra, aunque como es
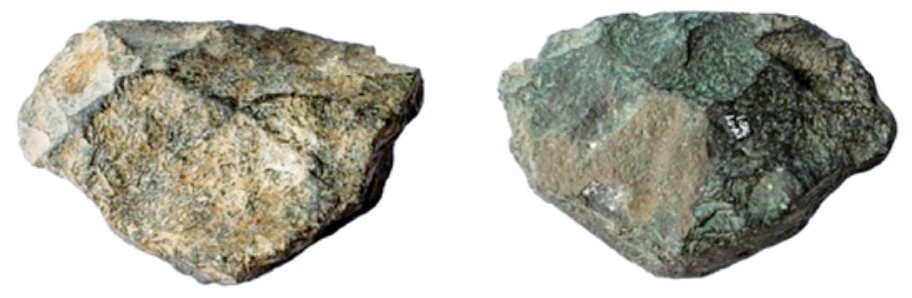

$5 \mathrm{~cm}$

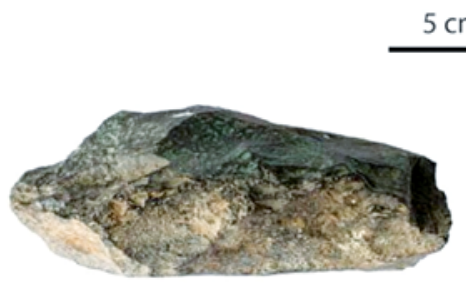

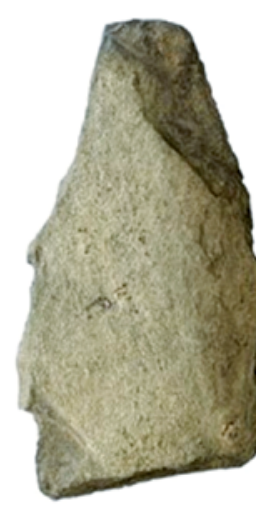
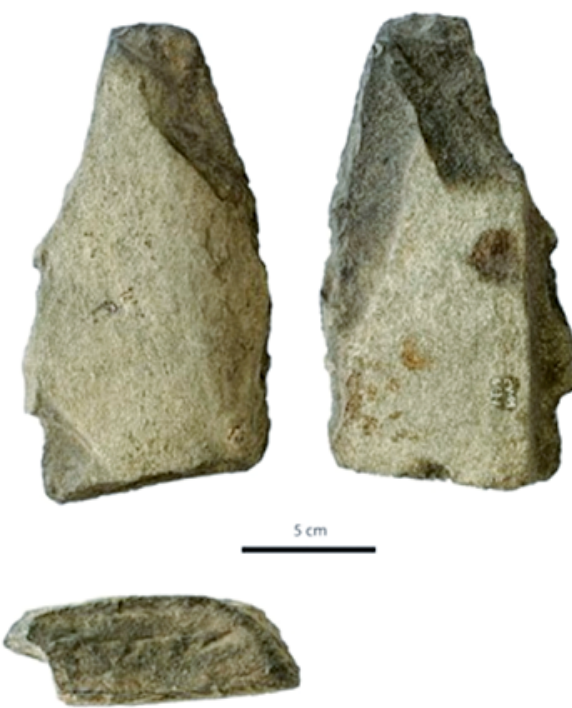

Fig. 4. Pico de basalto y pico de fonolita / Basalt and phonolithic picks. 
ligeramente traslúcida presenta matices verdes en las zonas más delgadas. Además tiene una granulometría muy fina y es muy brillante. Su córtex suele aparecer rodado, indicando que fue recuperada en contextos secundarios, al contrario de la que procede de las minas. El análisis geoquímico indicó que tiene una composición diferente, que la vincularía con un área fuente desconocida. En estos momentos se está procediendo a contrastar los datos obtenidos con técnicas tradicionales (ICP-OES e ICP-MS) (Buxeda et al., 2005).

Los tipos de soporte identificados más comunes son lascas bipolares y fragmentos (Tabla III). El pequeño tamaño de las obsidianas disponibles en la isla (Martín et al., 2001) es responsable de que la estrategia de talla más apropiada sea la bipolar. Así, mediante el contrapunto del yunque se obtienen en un solo gesto técnico piezas extraídas desde dos direcciones opuestas (Galván et al., 1992; Rodríguez, 1993). Los soportes de obsidiana presentan talones mayoritariamente corticales (32), pues el pequeño tamaño de los nódulos de los que se extraen dificulta la eliminación total del córtex. Por otra parte, su naturaleza vítrea y el empleo de la técnica bipolar favorece la formación de talones puntiformes y lineales.

El estudio funcional del material lítico tallado se ha visto dificultado por alteraciones posdeposicionales. Estas consisten en aristas redondeadas, playas de abrasión y, en el caso de los vidrios volcánicos, lustres y zonas mate.

Las lascas sobre RVGG no retocadas no presentan huellas de uso que hayamos podido identificar. Por el contrario entre las retocadas sí se han observado diversas clases de estigmas. Los filos de las dos muescas tienen desgaste y melladuras bifaciales asociadas. Las alteraciones posdeposicionales y la rugosidad de la fractura impiden determinar la naturaleza del material de contacto, aunque parece una materia dura y abrasiva (Rodríguez, 2009b). Una de las lascas con retoque continuo tiene asimismo un claro desgaste y melladuras unifaciales, vinculadas al mismo tipo de materia. Por último destaca el

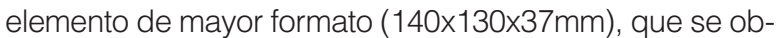
tuvo a partir de un canto rodado. En la reserva cortical de la cara dorsal existe una zona con un pulido intenso, asociado a estrías lineales desorganizadas. Estos estigmas se vinculan al uso anterior del canto en una labor de fricción sobre una materia no determinable. Posteriormente se obtuvo la lasca, que fue retocada en todo su perímetro, con negativos simples tendentes a abruptos. Los filos generados no presentan indicios claros de uso.

Por lo que respecta a los 3 picos, todos tienen huellas de uso muy desarrolladas en los ápices. Así, las aristas ligadas a los biseles tienen un gran desgaste confiriéndoles un aspecto redondeado. Además existen estrías perpendiculares y melladuras. Todo ello los vincula con un trabajo intenso de percusión y fricción sobre una materia dura y abrasiva que hemos asociado con la propia toba que sustenta al yacimiento. Otro tanto puede decirse del canto tallado unifacialmente. Su filo tiene un desgaste continuo muy desarrollado, creándose un bisel plano de ten- dencia convexa en el que se aprecian estrías perpendiculares. Estas huellas de uso se relacionan con actividades de raspado de la toba. Por lo tanto, pensamos que estos útiles han participado en labores de mantenimiento o construcción de silos, tanto en el labrado y piqueteado para abrir las oquedades, como en las acciones destinadas a regularizar sus paredes.

Por lo que respecta al análisis funcional de los $\mathrm{V}$, se han analizado 14 soportes (11 obsidianas-3 materia silícea). Este número es bajo en relación a las 137 piezas inventariadas, sin embargo se estudiaron todas aquellas que tuvieran al menos uno de sus filos con una delineación apta para realizar acciones longitudinales o transversales. Además, ya se ha señalado que las obsidianas tienen un componente cortical importante, que en muchas ocasiones ocupa los filos. Esto implica que no sean adecuadas para aquellas actividades que, a priori, serían las más apropiadas para esta materia. De los $11 \mathrm{VV}, 6$ son lascas bipolares, 3 unidireccionales, 1 cortical y 1 resto de talla kombewa, que puede proceder de una acción de talla bipolar sobre yunque. Entre las piezas bipolares hay dos que no fueron usadas y otro par con superficies alteradas que no permiten realizar un diagnóstico. Las dos restantes han servido para cortar materia blanda y abrasiva, posiblemente de tipo animal (Clemente et al., 2015). De las tres lascas unidireccionales dos no tienen huellas de uso y la tercera presenta alteraciones que la convierten en no analizable. Por último, la lasca kombewa no fue usada, mientras que la cortical se usó en un movimiento de raspado de una materia dura, posiblemente madera. Las tres lascas silíceas también se obtuvieron mediante la técnica bipolar. Sólo una tiene un filo con huellas de raspado de materia semidura con componente abrasivo, y quizás fue empleada en la limpieza de un hueso que conservara parte del tejido blando (Figura 5). Estos datos tan exiguos no permiten formular hipótesis concluyentes sobre las actividades realizadas con estos instrumentos.

\subsection{Grupo 2: Materiales de molturación}

Estas piezas se definen por su función, destinada a reducir cualquier materia a una fracción más pequeña, mediante machacado o fricción, pudiendo llegar a una pulverización total. Las categorías establecidas dependen de la morfología de las piezas y de la observación de estigmas de manufactura o uso. Se han analizado 45 fragmentos, que posteriormente se redujeron a 40 piezas, ya que se realizaron 4 remontajes en 3 útiles. Concretamente se ha reconstruido parcialmente un mortero de basalto y dos molinos naviformes, uno de igual materia prima y el otro realizado en ignimbrita (Figura 6).

Se documentan 19 piezas realizadas en RVGG, con una textura porfídica e inclusiones ocasionales de fenocristales. En este conjunto destacan 13 basaltos masivos, así como 6 piezas realizas en ignimbrita, algo interesante ya que es el único ejemplo del uso de esta materia prima en los yacimientos analizados. Quizá esa presencia se deba a la cercanía de los afloramientos que conocemos en el T.M. de Arucas, a 10 km del Cenobio. Estas RVGG se 


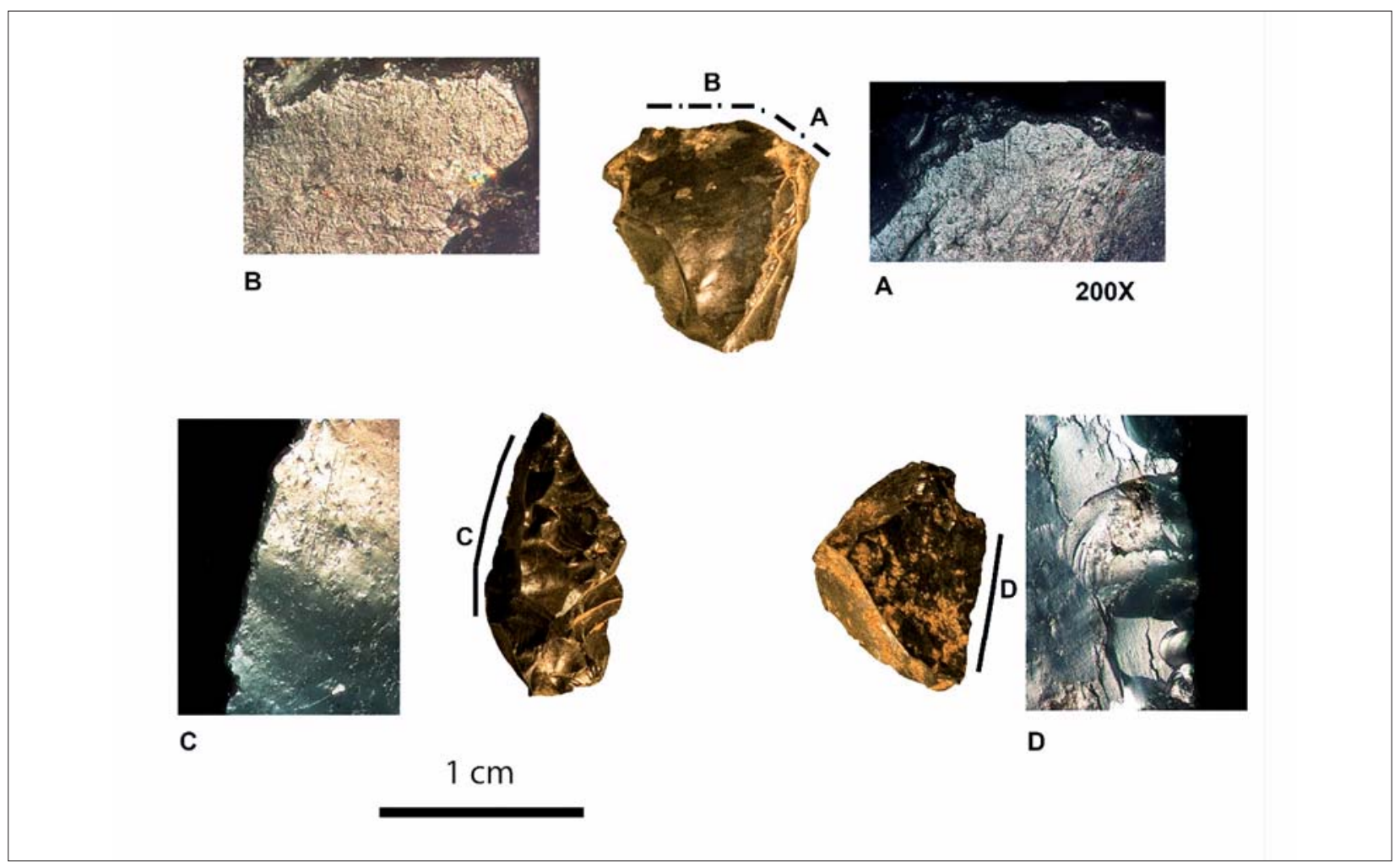

Fig. 5. Huellas de uso en lascas de obsidiana: pieza superior (A y B) raspado materia dura, posiblemente madera; Piezas inferiores (C y D) estigmas de corte de materia animal blanda / Use-wear in obsidian flakes: upper tool /A \& B) scraping hard material, possibly wood; down pieces (C \& D) cutting soft animal material.

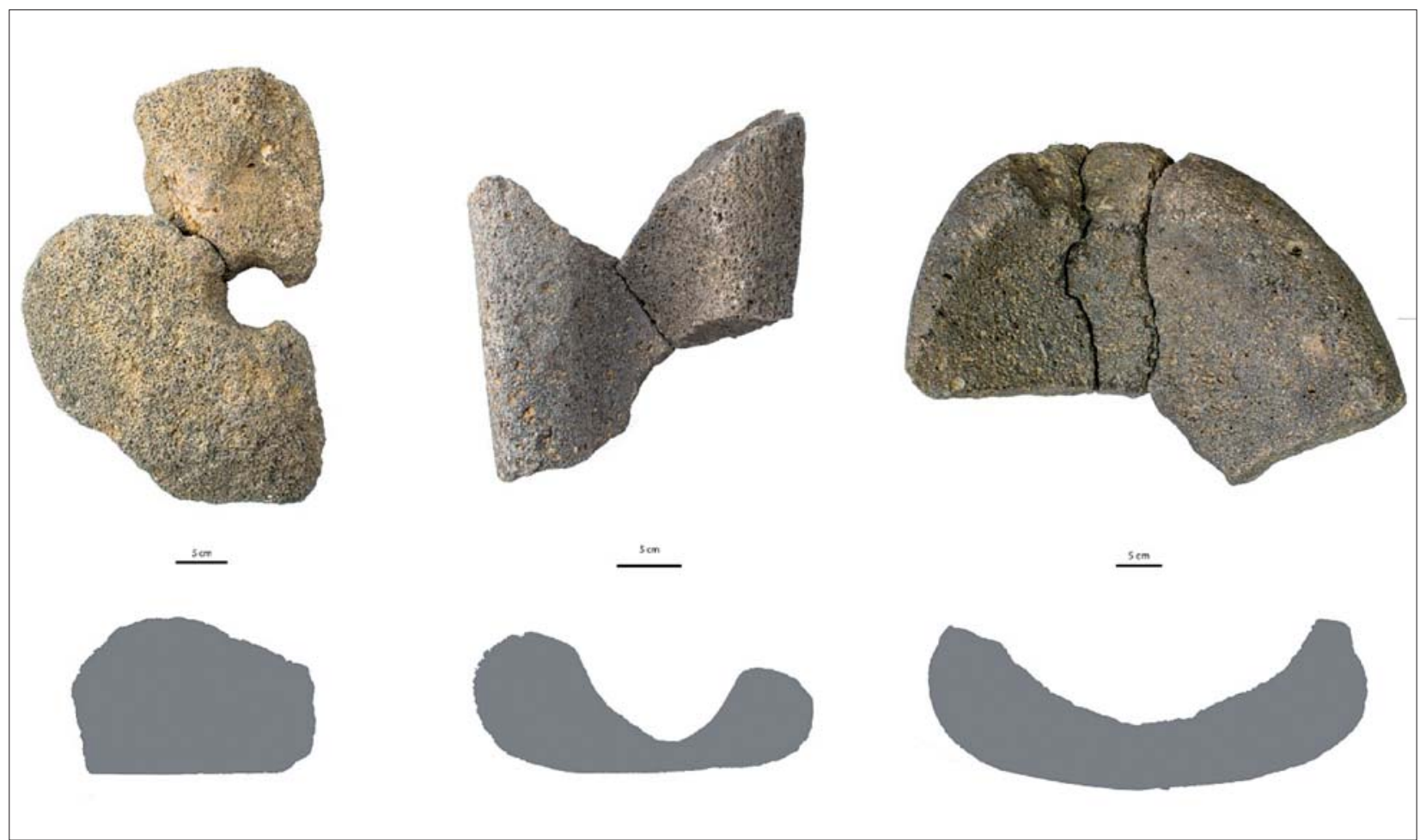

Fig. 6. Tipología de materiales de molturación de El Cenobio de Valerón. Molino de mano rotatorio; fragmento de molino naviforme y mortero/Typology of Grinding Stone tools from Cenobio of Valerón, fragments of a rotary quern, a back and forth quern and a mortar. 
caracterizan por su gran tenacidad y dureza, por lo que se usan especialmente en los molinos naviformes y los morteros, que requieren un soporte resistente que mitigue los impactos y roces generados en la fricción. Seguidamente destacan 15 artefactos elaborados en RVGG vesiculares. Su textura es adecuada, tanto para los elementos activos como los pasivos, porque la presencia de vacuolas genera siempre superficies muy rugosas, que se renuevan sin necesidad de reavivados intencionales. Finalmente hay 11 artefactos realizados en toba, cuyas propiedades varían en función del tamaño del lapilli que la compone, que presentan textura irregular y una resistencia variable con escasa compacidad (Rodríguez et al., 2001; Rodríguez y Martín, 2007a, Rodríguez et al., 2010). Pese a estos inconvenientes, en Gran Canaria se usó mucho la toba para elaborar molinos de mano rotatorios y el Cenobio no es una excepción. La toba utilizada en la manufactura de los molinos no se asemeja a la que actúa como soporte del granero, por lo que se descarta esta procedencia. Algunos resultados previos ${ }^{1}$ de los análisis geoquímicos en curso indican que al menos una de las piezas procede de la Cantera de Montaña Quemada, en el T.M. de Las Palmas de Gran Canaria, situada a 24 km, y que es una de las más cercanas entre las identificadas hasta ahora (Rodríguez et al., 2010).

\begin{tabular}{|l|c|c|c|c|}
\hline MMPP & \multicolumn{2}{|c|}{ CANTIDAD } & \multicolumn{2}{c|}{ PESO } \\
\hline RVGG & 19 & $41 \%$ & $68847 \mathrm{gr}$ & $41 \%$ \\
\hline RVGG vacuolar & 15 & $34 \%$ & $84923 \mathrm{gr}$ & $51 \%$ \\
\hline TOBA & 11 & $25 \%$ & $12895 \mathrm{gr}$ & $8 \%$ \\
\hline Total & 44 & $100 \%$ & $166665 \mathrm{gr}$ & $100 \%$ \\
\hline
\end{tabular}

Tabla 4: Materias primas y peso de Mat. Molturación / Raw material and weight grinding stone tools.

El estudio tecnológico de los soportes indica que las huellas de fabricación conservadas son marcas de labrado, fundamentalmente estrías de delineación lineal, anchas y poco profundas, que aparecen o formando haces. Aparecen especialmente en las partes no activas de los útiles, que no han sufrido un proceso de modificación intenso, es decir con escasas evidencias de abrasión y pulimento. Existen otras marcas, situadas en la base de algunas piezas, que relacionamos con las alteraciones que provocaba la manera de fijar los útiles. Se trata de estrías lineales anchas y profundas, más desordenadas, acompañadas de playas de abrasión y piqueteados.

Entre los materiales de molturación debemos establecer una distinción entre elementos activos y pasivos. Entre los primeros, destacan 11 muelas superiores de molinos de mano rotatorios, 11 manos y 1 pilón. Las muelas superiores realizan un movimiento rotatorio sobre la muela durmiente, a la que se unen a través de un vástago que impide el desplazamiento por la fuerza centrípeta de la pieza superior. Entre ellas 7 presentan morfología cilíndrica y 4 son troncocónicas. Además 3 muelas presentan hoyuelos de prehensión en la cara externa, en donde presumiblemente se insertaba un elemento intermedio, plausiblemente en madera que permitía ejercer la fuerza propulsora de la rotación de manera más eficiente. En los hoyuelos se detecta un gran desgaste asimétrico, generado por el roce de este elemento en la oquedad que indica la dirección de la rotación (Hamon, 2004; Alonso, 2014).

El orificio central se conserva en 9 muelas superiores. Hemos identificado variaciones morfológicas, que quizás tengan relación con el tamaño, la materia prima o la habilidad del labrante. Así, 5 perforaciones tienen morfología troncocónica, frente a 3 de tendencia bitroncocónica (en una pieza no se ha determinado), lo que indicaría que la apertura se realizó en unos casos desde una sola cara y en otros a partir de las dos, en un gesto de aproximación que favorecería la segunda forma. Por este orificio, además del eje que mantenía unidas ambas piezas, se introducía el grano para alimentar al molino. En ocasiones presenta una prolongación a modo de cuello, denominada gollete, que permite suministrar mayor cantidad de materia durante la molienda.

Las superficies activas de las muelas presentan una tendencia plana, con pequeñas irregularidades propias tanto de la microtopografía de la pieza, en el caso de los basaltos vesiculares, como de los piqueteados intencionales registrados en otras. El cálculo de sus áreas en $\mathrm{cm}^{2}$ es aproximado, debido a que se trata de fragmentos, pero en nuestra muestra oscila entre los 111 y $1230 \mathrm{~cm}^{2}$.

El resto de elementos activos identificados incluye las manos y pilones, ambos elementos no configurados intencionalmente. Las primeras se accionan con un movimiento de fricción, es decir, con una percusión de contacto, generalmente bidireccional. Normalmente se seleccionan cantos rodados, ya que su forma es idónea para el trabajo en útiles pasivos con una superficie activa plana o ligeramente cóncava, como los molinos naviformes. En el Cenobio de Valerón aparecen 11 manos, 7 de morfología esférica u ovoide y las 4 restantes de tendencia aplanada. Esta categoría puede incluir casos de reutilización de piezas rotas por accidentes, como muelas de molino fracturadas, por lo que su forma definitiva no es fruto de una configuración ex proffeso. Los pilones, también realizados sobre canto, se accionan mediante percusión sobre artefactos durmientes, como los morteros. Se trata de instrumentos con un índice de alargamiento ( $\mathrm{L}: \mathrm{A})$ superior al de las manos con una media de 1,24 (100x81 mm) frente a 1,13 de las manos ( $88 \times 78 \mathrm{~mm})$, y con un índice de carenado $(A: E)$ casi igual a 1 , mientras que en las manos es más variable (Laplace, 1968, 1972).

Atendiendo ahora a los elementos pasivos, en el yacimiento se documentan molinos naviformes y morteros. Resulta curioso que no se haya identificado ninguna muela inferior de molino rotativo. Éstas son más difíciles de reco-

\footnotetext{
${ }^{1}$ Comunicación personal de Jauma Buxeda i Garrigós que está analizando el conjunto en el Laboratorio de la Universitàt de Barcelona.
} 
nocer pues no tienen elementos característicos, como las muelas superiores (orificios de prehensión/gollete). En todo caso, existen 2 muelas indeterminadas cuyo reducido tamaño impide clasificarlas en este grupo (Naranjo y Rodríguez, 2014). No tenemos una explicación razonable para esta asimetría en la proporción entre muelas superiores e inferiores. Este fenómeno se repite en todos los yacimientos que estamos analizando. En nuestro programa experimental hemos comprobado que los elementos superiores experimentan una tasa de desgaste significativamente mayor, lo que implicaría que tendrían que reponerse con más asiduidad que los inferiores. Quizás esta circunstancia puede responder a esa sobrerrepresentación, de manera que se desechan más piezas activas que pasivas.

La segunda categoría la componen los molinos naviformes, caracterizados por una morfología elipsoidal u ovoide y una superficie activa alargada con sección en forma de $U$ abierta, de profundidad variable. En ellos se emplea una cinemática bidireccional o de vaivén ejercida con el útil activo, la mano. En el conjunto estudiado hay 8 , la mayoría fragmentados, lo que ha impedido determinar su longitud máxima. Sin embargo, las dimensiones de los fragmentos indican que estas piezas tenían un porte superior a los $30 \mathrm{~cm}$ de longitud. Estos instrumentos presentan niveles de amortización elevados, destacando una pieza, en la que se documenta un desgaste tan desarrollado que posiblemente sea responsable de su fractura.

La tercera categoría de elementos pasivos son los morteros. Estos artefactos son piezas durmientes idóneas para el machacado o triturado de sustancias, a través de una percusión directa con un pilón, de piedra o madera. En nuestro repertorio hay 12 ejemplos de morfología circular/oval y superficies activas en $U$ de diversa profundidad. Existen piezas configuradas intencionalmente, pero también se documentan algunas que no se han modificado. Las huellas de uso detectadas en uno y otro caso no permiten establecer diferencias funcionales claras. Sólo se ha podido determinar la morfología de 6 artefactos circulares/ovales pues el resto está muy fragmentado. En 5 piezas la morfología de las superficies activas es cóncava, con una profundidad media de $115 \mathrm{~mm}$. Asimismo, aparecen 3 ítems con una superficie activa de tendencia plana, aunque se trata de elementos muy fragmentados cuyo aspecto original es difícil de deducir. En estos útiles, también se ha hecho una estimación aproximada del área activa ya que tienen un alto grado de fragmentación, que oscila entre los 95 y los $24410 \mathrm{~cm}^{2}$. Sin embargo, cabe destacar la presencia de un gran mortero $(52 \times 29 \times 9 \mathrm{~cm})$, del que solo conservamos la mitad, que informa en cierta medida del volumen de materia trabajada en piezas de esta prestancia.

Una característica importante de estas piezas es el grosor de las superficies activas, que oscila entre 73 y 92 $\mathrm{mm}$, siendo significativamente mayor cuando se compara con los molinos rotatorios o de vaivén. Esto puede vincularse con la necesidad de resistir mejor los efectos de una percusión, mediante una base gruesa y resistente que mitigara los impactos y evitara fracturas indeseadas. Todos los morteros están realizados en RVGG, fundamentalmente basalto vesicular e ignimbrita.

El análisis funcional del conjunto ha tenido que afrontar los problemas derivados del grado de fragmentación de las piezas y las alteraciones de las superficies activas. Las razones para el nivel de fragmentación pueden ser diversas, pero entre ellas es evidente que algunas son fruto de un uso intensivo. Tampoco se descarta que muchos han podido verse afectados, por procesos postdeposicionales, como los ya descritos para las industrias líticas talladas. En todo caso, la mayoría de las piezas tiene un desgaste desarrollado, lo que indica una amortización importante de estos instrumentos.

Entre las muelas de molinos de toba se documenta un tipo de estigma particular, vinculado al reavivado de las zonas activas. Se caracteriza por la presencia de piqueteados y microhoyuelos, que aparecen especialmente en las áreas centrales de las superficies activas, que experimentan procesos de desgaste muy intensos. Ambos estigmas aumentan el poder mordiente de la pieza, restaurando la irregularidad de la superficie activa, que mengua la eficiencia en la molienda por la pérdida de granos.

Las huellas de uso varían según el tipo de útil. En el caso de los molinos de mano circulares se observa un gran desgaste de las superficies activas, especialmente visible en los elaborados en toba. Asimismo destacan las estrías lineales, que aparecen paralelas tanto al borde perimetral como al orificio central, que señalan la cinemática rotativa. Este tipo de estigmas se observan especialmente en el perímetro de la superficie activa de las muelas superiores. Los datos obtenidos a través del trabajo experimental y los vestigios de los diferentes yacimientos arqueológicos analizados, apuntan a que la fuerza ejercida con el elemento intermedio que facilita la rotación de la muela superior, favorece la aparición de estos estigmas. Esa zona experimenta una presión mayor, y por tanto proliferan estos estigmas (Figura 7). El constante movimiento y la pérdida de material entre ambas muelas generarían además del contacto con la sustancia procesada, el ocasional roce directo entre ambas muelas, creando zonas más alteradas. Además de estas trazas relacionadas con la cinemática del instrumento se han detectado estrías más finas con orientaciones variables, que cruzan y se superponen a las anteriores. Estos estigmas se han documentado en el programa experimental y pueden vincularse a la evacuación del producto final. La combinación de desgastes, estrías, así como de micropulidos brillantes, de trama cerrada y especialmente intensos en las aristas más destacadas de la microtopografía de las superficies activas, nos permite vincular estas huellas de uso al contacto con materia vegetal, seguramente cereal.

Para el caso de los molinos naviformes, el análisis traceológico de las superficies activas muestra la prevalencia de estrías largas y estrechas de profundidad variable organizadas en haces densos y orientadas de manera paralela al eje mayor del área de trabajo. En ocasiones se superponen o aparecen desordenadas, fruto de un uso 


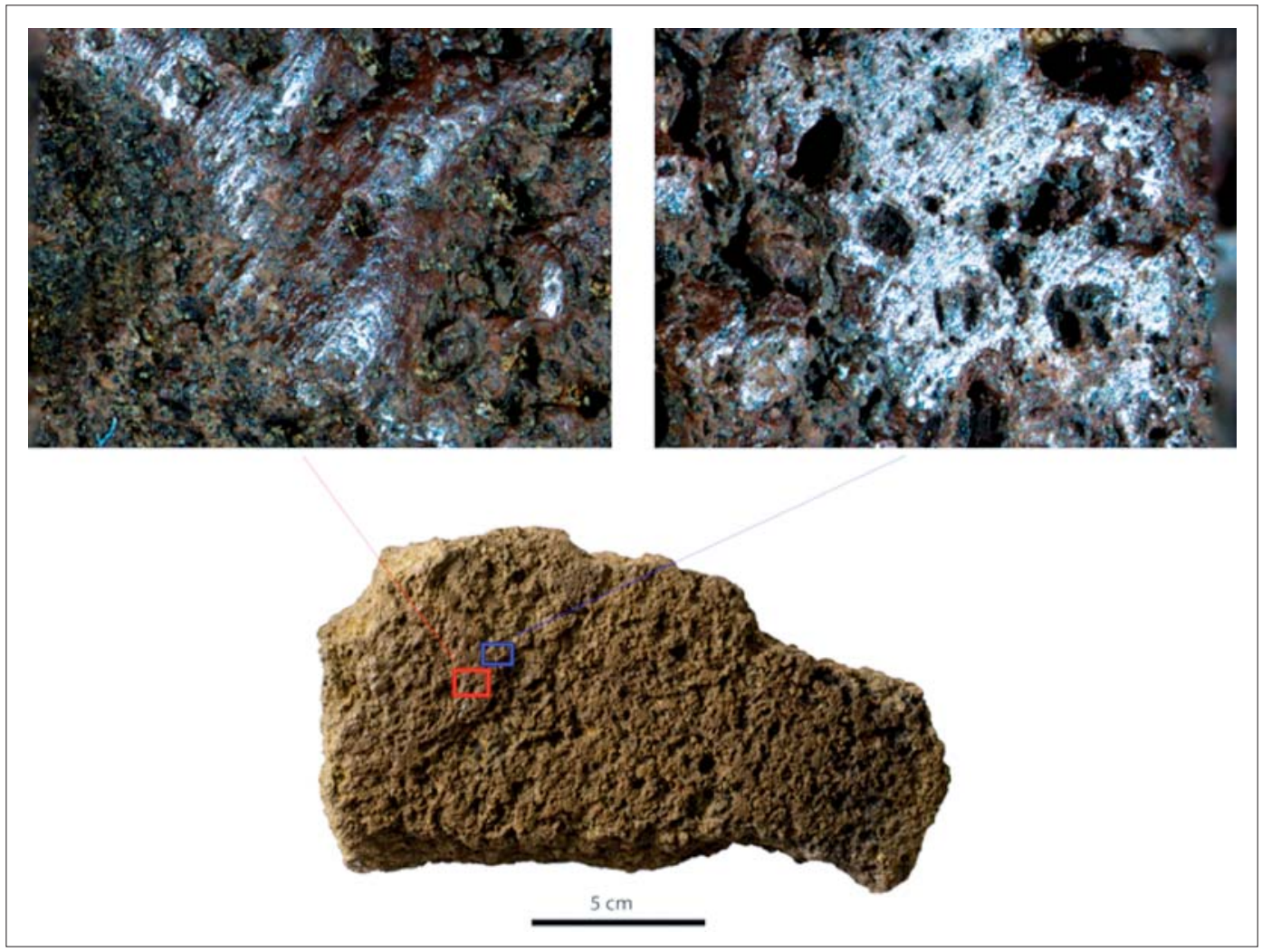

Fig. 7. Zonas brillantes y accidentes lineales en muela superior de molino rotatorio de toba $(20 \mathrm{x} / 30 \mathrm{x}) /$ Sheen areas and linear traces on upper wheel tuff quern (20x/30x).

complejo de este tipo de instrumento. Se aglomeran en la zona central de la pieza, donde es más continuo el movimiento de fricción realizado mediante la mano. En ocasiones aparece un desgaste significativo en las paredes del molino, fruto tanto de la morfología de la mano, como de la destreza y hábitos de la persona que muele.

Las huellas de uso registradas en las manos, consisten en estrías lineales con una disposición desordenada, ya que el útil no se mantiene en la misma posición durante la molienda. También hay zonas con playas de abrasión, que podrían relacionarse con episodios de contacto directo entre los dos elementos de molturación. Asimismo se documenta el desarrollo de áreas aplanadas con un micropulido intenso, que en ocasiones cubre toda la superficie de las piezas. Éste afecta a las zonas más elevadas de la microtopografía, confiriéndole un aspecto suave y aumentando su brillo. Estas características nos permiten vincularlos también al procesado de materias vegetales.

En los morteros, los estigmas de uso aparecen concentrados en la zona central de las superficies activas, donde destaca la presencia de microhoyuelos. Pese a esta concentración, se documentan también dispersos aleatoriamente por otras zonas de la superficie activa, algo relacionado con la naturaleza y cantidad de materia procesada. La gran incidencia de las fracturas, hoyuelos y microcráteres producidos por los impactos hace difícil la identificación de otros estigmas. No obstante, se han documentado estrías poco desarrolladas, posiblemente por el uso combinado de percusión y fricción. Se registran también pequeñas áreas con micropulidos poco desarrollados, cubiertos parcialmente por nuevos impactos. Esta superposición está bien documentada en nuestra colección experimental.

Este mismo hándicap se registra en el caso de los piIones. El análisis funcional los caracteriza por una cantidad enorme de machacaduras, destacando las fracturas estrelliformes, los microhoyuelos y la pérdida y redondeamiento de granos. En contadas ocasiones podemos observar estrías lineales aisladas, fruto de la combinación de la fricción y el machacado, atendiendo en este sentido tanto a la materia procesada, como al resultado deseado del producto final.

\subsection{Grupo 3: Otros útiles líticos}

Esta categoría incluye el resto de elementos líticos presentes en el granero, que no se han incluido en las precedentes. Se trata de un pico pulimentado, un útil alfarero, un conjunto de piezas no configuradas intencionalmente y por último, un grupo de artefactos de función indeterminada.

Entre el material recuperado en el Cenobio de Valerón figura un pico pulimentado. Se trata de un instrumento con la misma morfología y concebido para realizar tareas similares de percusión y labrado que los picos tallados identificados hasta ahora, pero que ha experimentado un proceso de pulimento posterior a su configuración (Rodríguez et al., 2006d; Rodríguez y Francisco 2012). Es una pieza de basalto, cuya preforma pudo obtenerse con un 
proceso preliminar de talla o directamente de un bloque detrítico poco espeso, aunque el acabado final se realizó mediante técnicas de abrasión y pulimento que han borrado los estigmas originales. Tiene la morfología estandarizada de este tipo de instrumentos, con apariencia de triángulo isósceles invertido y dos ápices activos. Además en la parte proximal de sus caras superior e inferior, a la que denominamos base, presenta una concavidad, interpretada como una adecuación para un posible sistema de enmangue. Esta pieza puede asociarse en este contexto a los picos tallados descritos anteriormente, y debe relacionarse con el labrado de la toba que actúa como soporte del granero, ya sea para excavar nuevas estructuras negativas, reparar o reacondicionar espacios existentes.

Estudios efectuados previamente sobre conjuntos líticos prehispánicos y etnográficos de Gran Canaria nos han llevado a clasificar el siguiente conjunto lítico, integrado por cantos rodados no modificados intencionalmente, como instrumentos de trabajo que intervienen en diversos momentos de la cadena operativa de la elaboración de la cerámica (Rodríguez et al., 2006a, 2006b; Rodríguez, 2009). En el Cenobio de Valerón aparece una única pieza, consistente en un pequeño canto rodado cubierto con un pulido de gran reflectividad y repleto de estrías. Además una de sus caras tiene un desgaste intenso, que ha modificado la curvatura natural del canto. Todo ello nos ha llevado a clasificarla como bruñidor/lisadera de almagría.

El resto de útiles no modificados intencionalmente lo integran 22 artefactos. Se trata de10 percutores, 9 piezas multifuncionales y 3 instrumentos de fricción activos.

Los percutores son de basalto afanítico, muy idóneo por su gran compacidad y resistencia a los impactos. Se trata de útiles de morfología variada que presentan claras huellas derivadas de su función. Estos estigmas consisten en pulidos y abrasiones, estrías, hendiduras, puntos de impacto sub-circulares, conos de percusión, microfracturas escamosas y fracturas (Cuartero, 2014). Hemos distinguido dos variantes, una de ellas presenta los impactos y machacaduras concentrados en el perímetro y/o en el eje longitudinal de la pieza, mientras que en la otra todas las superficies aparecen completamente repletas de machacaduras. Tal vez esta diferencia tenga que ver con un uso diferencial. Las huellas bien delimitadas están posiblemente ligadas al tallado de la piedra, mientras que las generalizadas pueden vincularse con la configuración de otros artefactos, como por ejemplo la manufactura por abujardado o el reavivado de molinos.

También se han definido nueve útiles multifuncionales, que presentan huellas de uso propias de los percutores, pero también otros estigmas que los vinculan a su empleo en otras tareas que no podemos determinar con certeza. En todo caso sí que podemos precisar que han sido utilizados combinando un movimiento de fricción y percusión. En la mayoría de los casos la combinación de estigmas permite establecer la diacronía de las acciones que realizaron. Por ejemplo, cuando los negativos de lascado invaden áreas con claros estigmas de pulido. Sin em- bargo, aparecen casos contrarios donde los negativos de lascado se difuminan bajo marcas de pulido. En otros instrumentos no hay superposición clara de huellas de uso, lo que impide establecer la cronología de su empleo o si corresponden a diversas fases de una misma cadena operativa o de varios trabajos diferentes.

El conjunto de 3 instrumentos de fricción activos no asociados a la molturación, se caracterizan por su textura, de grano irregular y su morfología poco estandarizada. Su uso se vincula a labores de abrasión, es decir, de percusión de contacto uni o bidireccional, con la intención de regularizar superficies y/o rasparlas. Precisamente la irregularidad de la topografía de sus superficies vuelve complicado establecer relaciones funcionales claras con actividades concretas. Tras el análisis traceológico, asociamos su uso con la regularización y pulimento de objetos de piedra, posiblemente para el mantenimiento de un mortero.

También se ha documentado un conjunto de 7 artefactos de funcionalidad desconocida, que no han sido configurados mediante técnicas de talla. Hay 5 piezas de morfología discoide, esto es de tendencia circular y aplanada, que presentan en su perímetro una hendidura o surco realizado intencionalmente. Asimismo existen 2 artefactos perforados (sin clara modificación intencional) y 1 soporte natural con una cavidad que le da apariencia de cuenco, y presenta restos de argamasa en su interior. No tenemos constancia de elementos similares en otros contextos de almacenamiento, no obstante las piezas con surcos aunque no de manera recurrente, suelen aparecer en el registro de la isla de Gran Canaria.

Para terminar el inventario de la industria lítica, debemos incluir 13 cantos de basalto olivínico, procedentes de la colección de El Museo Canario. En la mayoría de los casos tienen un pulimento muy acusado, de origen natural, sin que se detecten estigmas interpretables. Presentan unas dimensiones medias de $91 \times 73 \times 47$ mm y su morfología sugiere que son idóneos para ser usados como manos o incluso pilones, en el caso de los de mayor porte. Por ello consideramos que pueden ser una reserva intencional de materia prima para emplearlos posteriormente cuando fueran necesarios, incluso para tallar, ya que entre las lascas recuperadas hay varias que proceden claramente de cantos rodados. Hay que tener en cuenta que en los alrededores no se localiza este tipo de materia prima, por el carácter fonolítico de la geología de la zona (Pérez Torrado, 2000).

\subsection{Grupo 4: Material constructivo:}

En este apartado se va a tratar un conjunto de piezas de diversa morfología y tamaño, clasificados como elementos constructivos, que constituyen el grupo más numeroso del Cenobio de Valerón, con un total de 2354 piezas. Se trata de soportes de fractura plana que aparecen en gran número, y que no presentan ningún estigma que permita asociarlos a una actividad específica, pero que han sido llevados ex professo hasta el enclave, por lo que también los integramos en este estudio. 
Las piezas de mayor formato, se han vinculado con el cerramiento de los silos (Barroso y Marrero, 2009; Morales y Rodríguez, 2014), mientras que las de menores dimensiones, que en ocasiones hemos podido remontar con alguna de las primeras, pueden ser resultado de los arreglos y reconfiguraciones que se les practicaban, para acomodar su morfología a las necesidades de uso. La mayoría de este conjunto está integrado por rocas fonolíticas afaníticas, que serían seleccionadas del cauce del Barranco de Valerón. Una de las ventajas que presenta esta materia prima para emplearla como material constructivo, es su textura exfoliada, que propicia fracturas de tendencia plana, lo que facilita la unión entre distintos soportes. También hay elementos elaborados en otras materias primas: 48 piezas en una roca basáltica de color muy oscuro, 30 elementos de traquita y 9 soportes tefríticos.

Las grandes lajas presentes en el Cenobio de Valerón se han encontrado concentradas en la zona 1 y el área de visera. Están claramente fuera de sus lugares originales a pesar de su tamaño y peso, con un grosor medio en torno a los 12-14 cm, como resultado de los diversos trabajos de acondicionamiento y limpieza efectuados en el granero. Se ha propuesto que pudieron usarse como cerramiento de los silos (Barroso y Quevedo, 2009), sin embargo no ha aparecido ninguna in situ. Es cierto que hay cavidades cuyas bocas presentan ranuras o rebajes destinados a facilitar este cerramiento, pero no sabemos de qué naturaleza pudo ser pues solo se conocen puertas de madera en otros contextos de la isla (Cuenca, 2014). Sin embargo no se puede descartar que, según el tipo de materiales almacenados, el tiempo que se propusiera para conservarlos intactos, e incluso la naturaleza particular o colectiva del silo, variara la forma de cerrar o sellar la estructura. En todo caso, es curiosa la abundancia de estos soportes, y sobre todo la inmensa cantidad de pequeños fragmentos desprendidos de las grandes lajas, de forma casual o intencional y que se conservan en el granero.

Las piezas más pequeñas no sólo provienen de los desechos de la configuración de las grandes lajas, también podrían ser calzos que ayudaran a mejorar los cerramientos de los silos, o de otro tipo de paramentos que se erigieran en el sitio, e incluso para ayudar a fijar postes o columnas cuyos negativos son numerosos en El Cenobio. En este sentido, es importante señalar que hemos detectado restos de una especie de argamasa de coloración muy clara en 66 piezas.

\section{4.- DISCUSIÓN}

Un primer elemento de reflexión atañe a la validez que pueden tener nuestros resultados para comprender el funcionamiento de los yacimientos arqueológicos interpretados como graneros excavados en la toba. Hasta ahora nunca se ha localizado una celda intacta en ninguno de estos lugares, por lo que todos ellos proporcionan vestigios parciales, más o menos alterados por la acción antrópica y natural de muchos siglos. Este es un problema al que nos hemos enfrentado cuando se han realizado los análisis arqueobotánicos, del que se han derivado diversos test para ayudar a discernir entre los restos vegetales antiguos, depositados intencionalmente en los silos y aquellos otros llegados a las estructuras mediante la intervención de animales o la propia acción eólica (Morales et al., 2014). En todo caso, la mayoría de las evidencias botánicas que se conservan en los graneros, pasaron desapercibidas para los visitantes que los frecuentaron durante siglos, por lo que no cabe plantearse que fueran desplazadas o reubicadas intencionalmente en otros recintos del mismo conjunto. El factor humano intervino cuando ciertas cavidades fueron reaprovechadas como corrales en tiempos no muy lejanos (por ejemplo en Acusa). Tampoco se debe descartar que alguna de estas estructuras negativas fuera amortizada como basurero o como emplazamiento de otros elementos desconocidos. En este sentido, uno de los usos probables de algunas celdas, ya recogido en descripciones como la presentada en la introducción de este trabajo, podría ser el espacio sepulcral. Sirva como ejemplo que en el informe realizado en 1944 por Jiménez Sánchez aparece inventariado un fémur humano. Sin embargo, los trabajos arqueológicos actuales no localizaron ningún material de estas características, aunque sí evidencias de fauna antigua y moderna, llegada al sitio ya sea por accidente o de forma intencionada. No obstante, no sería descabellado pensar que en algún momento determinados silos que integran el granero, funcionaran como necrópolis, como lo hicieran sus semejantes norteafricanos (Montagne, 1929; Delaigne, et al., 2011).

Pero, ¿qué pasaría con los artefactos de piedra? Ya se ha comentado, que la intervención de Sebastián Jiménez Sánchez propició la recogida de algunas piezas, fundamentalmente elementos de molturación, cantos rodados y algún soporte tallado de gran tamaño. En nuestra experiencia, las industrias líticas talladas, si no son muy espectaculares, no suelen reconocerse como evidencias arqueológicas, sobre todo si se confeccionan en RVGG o si se trata de obsidianas muy pequeñas, como las localizadas en la isla. Los productos tallados sobre RVGG, aparecen distribuidos por todo el yacimiento (Figura 8).Un aspecto destacado, es que aparecen 4 útiles tallados en 2 de los silos que han sido datados a través de restos de cebada e higos (Tabla I). Concretamente se trata de tres lascas retocadas y un pico. Las lascas están precisamente entre las piezas talladas de mayores dimensiones localizadas en el enclave.

Con respecto a los $\mathrm{V}$ aparecen concentrados en las zonas 4 (25 piezas); 5 (20 piezas); 8 (105 piezas); 9 (53 piezas) y 11 (44 piezas). La zona 8 del yacimiento es la más amplia y la que cuenta por tanto con mayor número de silos. Posiblemente estas piezas no han sufrido demasiados procesos de circulación postdeposicionales debido a su pequeño tamaño, y fueran éstas las zonas originales donde se tallaban o reavivaban los filos para realizar alguna actividad relacionada con las realizadas en un granero de estas características. La gran abundancia de restos de talla y fragmentos de obsidiana nos sugiere que quizá en el granero se tallaran piezas que luego se deri- 


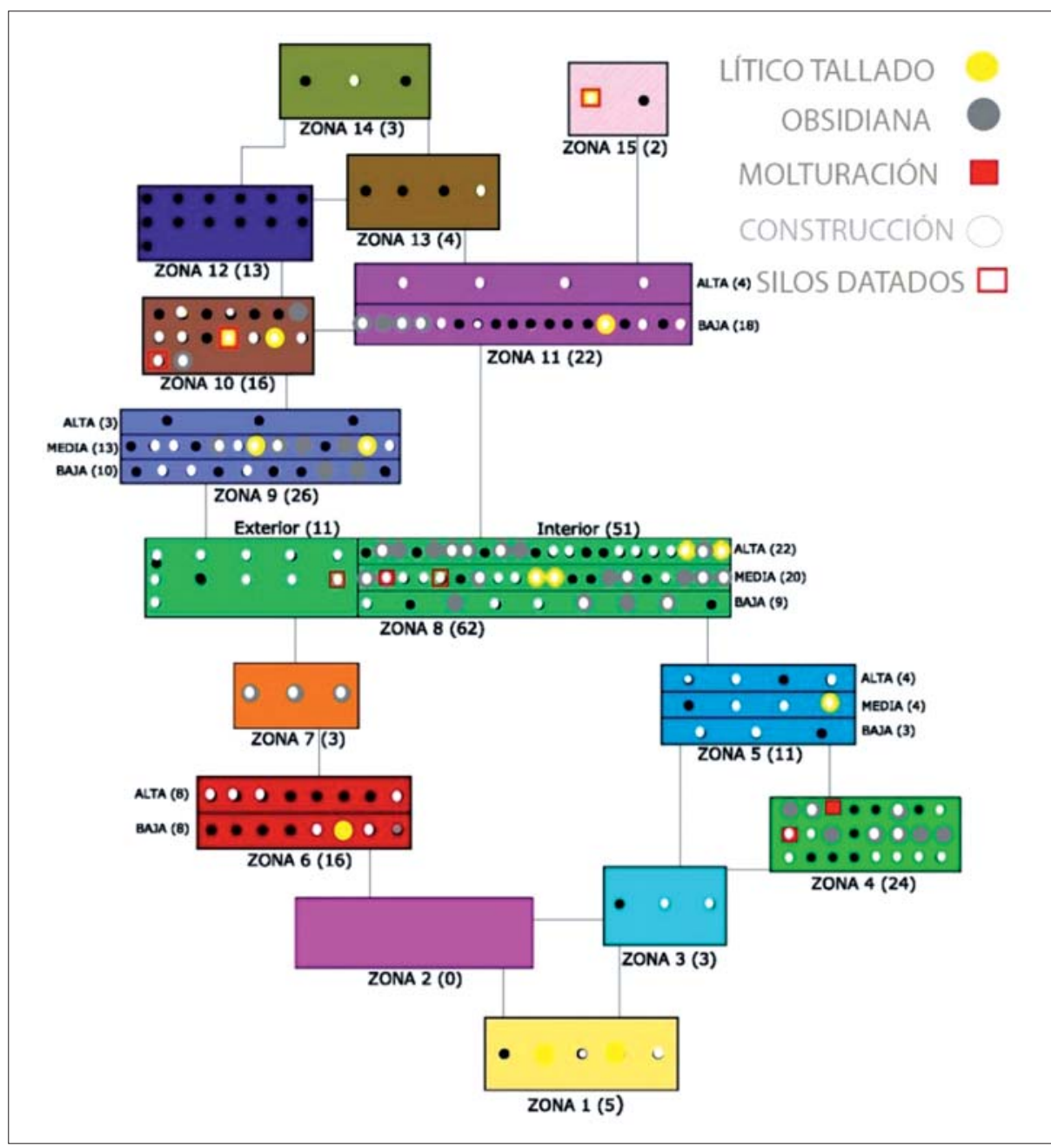

Fig. 8. Plano de dispersión de los materiales según zonas/ Scattering plane of lithic implements according to different areas. varían a otros sitios y allí solo quedaran los desechos. Ya se ha comentado la escasez de elementos con huellas de uso y cómo no se registra ningún trabajo de forma reiterada, por lo que esas piezas usadas son verdaderamente testimoniales, aunque llama la atención la ausencia de estigmas vinculados al procesado de los cereales, que son el principal bien que se guardaba en los graneros.

De los 40 útiles de molienda, 24 proceden de la intervención realizada por Arqueocanaria S.L. en 2009. Sabemos que aparecieron concentrados exclusivamente en tres de los cientos de silos que componen el yacimiento, exceptuando una pieza que fue localizada en la zona de visera. Este hecho indica su posición secundaria quizá con motivo de una limpieza (Figura 5). Estos movimientos postdeposicionales, impiden establecer cualquier intento de análisis espacial.

Sin embargo, todas las materias primas de los artefactos líticos se recogieron fuera del granero. Unas de las inmediaciones del Barranco de Valerón, como es el caso de los soportes de fractura plana de fonolita, algunos cantos rodados o incluso algún elemento detrítico de basalto vacuolar recuperados del cauce o laderas del barranco.
En otros casos, las áreas fuente tienen un emplazamiento más lejano, como los complejos de minas de obsidiana de las montañas de Hogarzales y El Cedro. El acceso al sitio no era fácil, ya que este tipo de enclaves se seleccionan precisamente por esa cualidad. El peso de algunos de estos elementos era muy considerable, como es el caso de los soportes de fractura plana de fonolita y, en menor medida, de alguno de los propios morteros, que en ocasiones superan los $20 \mathrm{~kg}$.

Las dificultades inherentes a la manipulación de estas piezas sólo nos permiten comprender por qué no fueron extraídas del Cenobio como otros objetos, no obstante, no escaparon a su desplazamiento de los lugares originales.

Teniendo en cuenta todos los problemas de representatividad que hemos comentado más arriba, la cuestión es ¿cuáles eran las funciones que desempeñaban los diversos artefactos aquí presentados? Por una parte tenemos un conjunto de instrumentos tallados de gran formato, los picos, el canto y tres lascas con huellas de uso claramente relacionadas con la acción de percutir o raspar toba. Estas piezas pueden ser los restos de aquellos útiles empleados para crear el granero e ir ampliándolo, repa- 
rándolo o reacondicionándolo. En todo caso, parecen estar más relacionadas con actividades que desarrollaron allí, aunque no podamos descartar que alguna fuera desplazada hasta el Cenobio de Valerón para guardarla en una de sus cavidades como reserva y emplearla en futuros trabajos. Entre las industrias líticas talladas más pequeñas son escasos los útiles retocados o con huellas de uso, mientras que predominan los restos de talla, lo que podría aplicarse también a los pequeños restos de fractura plana que se han descrito más arriba. Esto implicaría que en el granero se produjeron actividades de configuración o reavivado de útiles o de elementos constructivos, los cuales pudieron emplearse "in situ" como es el caso de algunas obsidianas, o también desplazarse a otros lugares (y aquí no se puede descartar que esta acción se produjera unos cientos de años después de que el sitio dejara de cumplir su función). Sin embargo, no nos resistimos a plantear que quizá en el caso de los vidrios volcánicos el granero funcionara como un centro receptor de esta materia prima. Posteriormente allí se realizaran algunas labores de talla para crear los soportes que luego se transportarían hasta los poblados.

No deja de llamar la atención que ningún instrumento tallado pueda vincularse con el corte de materias vegetales. Este dato contrasta con la claridad de las huellas de corte que aparecen en los raquis de cereal documentados en otros graneros, como el de Acusa (Morales et al., 2014) o el de Temisas (Henríquez, 2015) y que indican que el trigo y la cebada se guardaban en sus espigas, las cuales se separaban de la paja mediante un corte. Esa labor parece haberse desarrollado en otro lugar, seguramente en los propios campos de cultivo o quizá en algún recinto dedicado al procesado primario de la cosecha. Sin embargo, la presencia en el registro material que hemos estudiado de instrumentos dedicados a la molturación puede indicar que en el granero se procesaba una parte de lo almacenado. Como en otras ocasiones, no se puede afirmar que todos los molinos, morteros o manos localizados en el Cenobio de Valerón correspondan a piezas empleadas exclusivamente allí, ya que algunos podrían formar parte de ajuares custodiados en alguna de las estructuras pero destinados a ser usados en otros sitios, o simplemente, relegados al olvido por sus propietarios. Sin embargo, pensamos que esta categoría de objetos presenta unas características que lo diferencian particularmente del resto de útiles de esta tipología que estamos estudiando en otros yacimientos de la isla, fundamentalmente interpretados como contextos domésticos. Aunque la tipología de los aquí localizados es similar en todos los yacimientos analizados, su tipometría destaca notoriamente del resto del material, ya que en todas las categorías identificadas las dimensiones son mayores.

Por ejemplo, en el caso de los molinos rotatorios cuyo diámetro original ha podido medirse, las piezas oscilan entre los 32,4 y los 47,6 cm y el grosor de las muelas tiene unas medidas entre los 33 y $85 \mathrm{~mm}$ (si se discrimina entre materias primas, los de toba tienen una media de $35 \mathrm{~mm}$ y los de basalto de $60 \mathrm{~mm}$ ). Este dato los sitúa muy por encima de la media de los otros yacimientos que han sido estudiados, aunque pueden documentarse algunas excepciones, como La Cerera, donde los diámetros medios de los molinos de basalto alcanzan $37 \mathrm{~cm}$.

Otro tanto puede decirse de los grandes morteros de morfología circular/oval. Su tipometría se ha calculado en los casos en los que ha sido posible, oscilando su diámetro entre los 35 y los más de $60 \mathrm{~cm}$. Si los comparamos con los morteros del resto de yacimientos analizados (Los Caserones, El Pajar, La Cerera, Los Barros, Cueva Pintada (estructura 12), San Antón y El Tejar), las dimensiones se sitúan en torno los $30 \mathrm{~cm}$ de largo. En el caso de El Cenobio de Valerón tenemos morteros con más de $50 \mathrm{~cm}$ de largo, comparables únicamente a los localizados en Cueva Pintada en las estructuras 20 y 30, que superan los $60 \mathrm{~cm}$. Estas dimensiones dan una idea de la importancia de este tipo de instrumentos y de su capacidad, que propicia un alto rendimiento en el procesado de alimentos básicos en la dieta (Morales, 2006; Adams et al., 2009).

Con respecto a los molinos de vaivén su tipometría es poco representativa por la escasez de muestras. En general esta diferencia de tamaño entre el material de molturación del granero y de los contextos domésticos puede indicar quizá que en El Cenobio de Valerón se procesaba al menos una parte de los cereales de una forma intensiva y que de allí partían ya transformados en harina.

\section{5.- CONCLUSIONES}

Este estudio representa una primera aproximación al análisis de un repertorio material amplio pero escasamente estudiado, en el que se incluyen elementos vinculados claramente a actividades específicas, con otros con una función desconocida. Sin embargo, El Cenobio de Valerón, que es el mayor espacio de almacenamiento que se conoce en todo el contexto de la arqueología preeuropea de la isla de Gran Canaria, puede servir para seguir profundizando en la interpretación que se da a estos enclaves.

La incógnita principal que se debería responder es la naturaleza de la propiedad de los productos custodiados en estos sitios, pues su función como lugares destinados al almacenamiento no presenta dudas para nosotras. Los análisis realizados sobre los restos vegetales, así como el hallazgo de insectos claramente vinculados a los procesos de almacenamiento, e incluso de plantas destinadas a prevenir este tipo de plagas (Morales et al., 2014) vienen a confirmar las interpretaciones previas, basadas en los textos etnohistóricos y el estudio de la propia estructura de estos espacios. Con el estudio carpológico y entomológico del granero de Acusa, los análisis en marcha del granero de Temisas (Henríquez, 2015) y del propio Cenobio de Valerón, los datos parecen apuntar a que en prácticamente todos los silos se custodiaba todo el elenco de especies cultivadas por los antiguos canarios y también algunas plantas silvestres. Esa promiscuidad indicaría quizá que cada cavidad debería 
pertenecer a una unidad doméstica, que almacenaría en ella los excedentes que pensara consumir en un espacio de tiempo lo suficientemente dilatado como para plantearse guardarlos fuera del propio recinto de la "casa". Esta forma de proceder coincidiría con las descripciones etnográficas que se han realizado en algunos graneros fortificados de Marruecos, principalmente. El minucioso trabajo realizado en dos enclaves del AntiAtlas marroquí (Delaigue et al., 2006, 2011), muestra que las celdas son propiedades familiares (no discutiremos aquí las variantes y vicisitudes que pudieron experimentar) en las que se custodiaban no sólo la cosecha, sino toda suerte de artefactos de valor hasta que cayeron en desuso y se convirtieron en trasteros o desvanes.

De las evidencias líticas se desprende que no parecen existir instrumentos ligados a la cosecha y procesado de cereales. Solo se detectó una lasca que había raspado madera, un trabajo que puede vincularse con actividades de mantenimiento ligadas a variados artefactos. De forma inversa, las escasas determinaciones que hemos realizado documentan el procesado de materias blandas y de origen animal, un producto que no ha sido señalado hasta ahora como posible integrante de los bienes custodiados en los graneros. Este dato puede ser explicado de dos maneras: las piezas corresponden a labores destinadas al procesado de carne para su conservación o bien son el resultado de acciones puntuales de consumo por parte de las personas que custodiaban o visitaban los silos. Ambas interpretaciones presentan problemas. Por una parte, parece más lógico que las carnes destinadas a hacer tocinas u otro procedimiento de conservación fuesen preparadas y conservadas en los contextos domésticos. La excepción podrían ser aquellos bienes vinculados con los comentados "diezmos" (Gómez Escudero [1484] 1936:82) que constituían esos excedentes administrados por las élites. La forma en que esos productos se procesaban, dónde se realizaba ese trabajo y cómo se custodiaban es una incógnita, pero no vemos por qué no pudo efectuarse, al menos en parte, en los graneros. La otra opción también es viable y ambas necesitan, además de un mayor contingente de piezas analizadas, de un buen análisis tafonómico y de distribución espacial. Está claro que el Cenobio de Valerón fue erigido gracias una ingente inversión de fuerza de trabajo, cuya organización pudo ser comunal o auspiciada por una clase dirigente. En el caso de los graneros fortificados del Anti-Atlas, se documenta que estos se construían y custodiaban mediante un trabajo comunal, que luego eran gestionados por un consejo también comunal y eran vigilados por una persona que sólo permitía el acceso a los propietarios de cada celda. La memoria colectiva y las evidencias de las primeras fases constructivas de los graneros de lb Aysa y Uggluy inciden en la voluntad de reflejar una sociedad igualitaria, que los documentos escritos y las fases constructivas recientes contradicen. En el caso del Cenobio de Valerón existen algunos datos que podrían estar indicando que no todas las estructuras negativas responden al mismo modelo de "despensa" familiar. No podemos descartar totalmente que varias de ellas pertenecieran a una misma familia preeminente o que respondieran a una voluntad de conservar los granos más allá de lo que corresponde a un ciclo agrario anual. Si la interpretación del equipo de trabajo que realizó las tareas de restauración y limpieza del yacimiento es correcta, la presencia de grandes lajas podría ser una ventaja si se quería mantener bien sellado algún silo, sobre todo si se tenía previsto un almacenaje prolongado. Y esa circunstancia podría tener varias explicaciones. $\mathrm{O}$ bien, tal y como se menciona en alguno de los documentos escritos coetáneos a la conquista de Gran Canaria, se destinaría a reserva para prevenir años difíciles, o bien podría ser una manera de atesorar productos, recabados por el sistema de diezmo con los que poder negociar una contraprestación.

No obstante necesitamos analizar otros contextos de almacenamiento, que nos permitan contrastar los resultados obtenidos tras el análisis de la industria lítica de El Cenobio de Valerón, para poder ratificar y conocer nuevos usos y formas de gestión llevadas a cabo en este tipo de yacimientos, los graneros fortificados que reflejan aspectos muy importantes de la estructura socioeconómica preeuropea de los antiguos canarios.

\section{6.- AGRADECIMIENTOS}

Este trabajo se ha realizado en el marco del proyecto de investigación HAR2013-41934. Yurena Naranjo es beneficiaria de una beca FPI del Ministerio de Economía y Competitividad. Queremos agradecer la colaboración de la empresa Arquecanarias S.L.

\section{BIBLIOGRAFÍA}

ADAMS, J.L., DELGADO, S., DUBREUIL, L., HAMON, C., PLISSON, H. \& RISH, R.

2009 Functional analysis of macro-lithic artefacts: a focus on working surfaces, in STERNKE, F., EIGELAND, L. \& COSTA, L.-J. (eds.). Proceedings of the XV World Congress (Lisbon, 4-9 September 2006).

\section{ALONSO , N.}

1999 De la llavor a la farina. Els processos agrícoles protohistòrics a la Catalunya occidental. Monographies d'Archéologie Mediterranéenne, 4. Lattes.

2014 Etnoarqueología del proceso de molienda manual de cereales: grañones, sémolas y harinas. Revista d'Arqueologia de Ponent 24: 113-36.

ATOCHE, $P$.

1993 El poblamiento prehistórico de Lanzarote. Aproximación a un modelo insular de ocupación del territorio. Tabona VIII (t. I), 77-92.

ATOCHE, P. \& MARTÍN, J.

1999 Canarias en la expansión fenicio-púnica por el África Atlántica, en I/ Congreso de Arqueología Peninsular (Zamora, 1996) Tomo III. 485-500. Universidad de Alcalá. Fundación Rei Afonso Henriques. 
ATOCHE, P. \& RAMÍREZ, Mª.A.

2001 Canarias en la etapa anterior a la conquista bajomedieval (circa s. VI a.C. al s. XV d.C.): Colonización y manifestaciones culturales. Arte en Canarias [siglos XV-XIX]. Una mirada retrospectiva. Tomo I, 43-95. Tomo II, 475-479. Gobierno de Canarias. Consejería de Educación, Cultura y Deportes. Viceconsejería de Cultura y Deportes. Dirección General de Cultura. Madrid.

BALBíN, R., BUENO, P., GONZÁLEZ, R. \& ARCO, Mª C.

1995 Datos sobre la colonización púnica de las Islas Canarias. Eres Arqueología 6(1), 7-28.

BARROSO, V. \& MARRERO, C.

2009 Memoria de restauración del Cenobio de Valerón.

BATLLORI Y LORENZO, J.

1901 Revista del Museo Canario Tomo X, año 6, n. 103.

BAUCELLS, S.

2004 Crónicas, Historias, Relaciones y otros relatos: las fuentes narrativas del proceso de interacción cultural entre aborígenes canarios y europeos (siglos XIV a XVII). Fundación Caja Rural de Canarias, Chil y Naranjo 2003. Gran Canaria.

BOFILL, M.

2014 Inicio y consolidación de las prácticas agrícolas durante el neolítico en el Levante mediterráneo (septentrional y central): el proceso de molienda y trituración a partir del análisis funcional del instrumental macrolítico. Tesis doctoral inédita. Universitat Autònoma de Barcelona.

BUXEDA, J.; KILIKOGLOU, V; MARTíN, E.; RODRÍGUEZ, A. \& MADRID, A.

2005 Preliminary results on obsidians from Gran Canaria. Geoarchaeological and Bioarchaeological Studies 3: 49-51

CASTILLO, P.A. del

1848 Descripción histórica y geográfica de las Islas de Canaria. Imprenta Isleña. Santa Cruz de Tenerife.

CLEMENTE, I; LAZUÉN, T; ASTRUC, L. \& RODRÍGUEZ, A.

2015 Use-wear analysis of nonflint lithic raw materials: the cases of quartz/quartzite and obsidian. En J.M. Marreiros, J.F. Gibaja Bao, N. F. Bicho eds Use-Wear and Residue Analysis in Archaeology. Ed. Springer, pp. 59-81.

\section{CUARTERO, F.}

2014 Percutores y retocadores: Interpretación de comportamientos técnicos en el Paleolítico Medio peninsular desde el análisis de instrumental del tallador. Tesis Doctoral inédita. Universidad Autónoma de Madrid.

CUENCA, J.; GÓMEZ, D. \& ABREU, I.

2014 La intervención arqueológica en el complejo troglodita de Cuevas de La Audiencia, Temisas. Actas del XXI Coloquio de Historia Canario Americano (en prensa).

DELAIGNE, M.C; ONRUBIA, J; AMARIR, A. \& BOKBOT, Y.

2006 Etnoarqueologí de los graneros fortificados Magrebíes: El agadir de Id Aysa (Amtudi, Marruecos). Treballs d'Etoarqueología 6. CSIC. Madrid.
DELAIGNE, M.C; ONRUBIA, J; BOKBOT, Y. \&AMARIR, A.

2011 Une technique d'engrangement, un symbole perché. Tecniques \& Culture 57, 182-201.

\section{DUBREIL, L.}

2004 Long-term trends in Natufian subsistence: a use wear analysis of ground tools. Journal of Archaeological Science 31(11), 1613-1629.

GALVÁN, B; RODRíGUEZ, A.C.\& FRANCISCO, M.I.

1987 Propuesta metodológica para el estudio de las industrias líticas talladas de las islas Canarias. Tabona VI, 9-89.

GALVÁN, B.; HERNÁNDEZ, C.M.; FRANCISCO, M.I. \& RODRÍGUEZ, A.C.

1992 La industria obsidiánica, en GALVÁN, B. (ed). El yacimiento de la cueva de Las Fuentes (Buenavista del NorteTenerife). 87-169. Cabildo de Tenerife.

\section{GALVÁN, B. \& HERNÁNDEZ, C. M.}

1996 Aproximación a los Sistemas de captación y transformación de las industrias líticas canarias. Tabona IX, 45-73.

\section{GÓMEZ ESCUDERO, P.}

1936 Historia de la Conquista de Gran Canaria. Notas de Dacio Victoriano Darias Padrón. El Norte.

GONZÁLEZ, J.E. \& IBÁÑEZ, J.J.

1994 Metodología de Análisis Funcional de instrumentos tallados en sílex. Universidad de Deusto.

HERNÁNDEZ, P.

1944 Cuevas de Valerón. Ni cenobio ni granero. Revista de Historia $65,78-80$.

JIMÉNEZ, S.

1943 Silo o Agadir colectivo de Valerón. Informe citado como Revista Canaria en Digitalización realizada por la Biblioteca de la ULPGC (Repositorio Digital). 24-81.

1944 Silo colectivo prehispánico o Agadir de Valerón. Revista de Historia 65, Tomo X, año 17, 24-31.

1946 Excavaciones arqueológicas en Gran Canaria, de los planes nacionales de 1942, 1943 y 1944. Informes y memorias de la Comisaría general de Excavaciones Arqueológicas, n. 11. Madrid.

KEELEY, L.H.

1980 Experimental determination of stone tool uses. A microwear analysis. Prehistory, Archaeology and Ecology Series. The University of Chicago Press.

LAPLACE, G.

1968 Recherches de typologie analytique 1968. Roma.

1972 Cahiers de typologie analytique. Centre de Palethnologie Stratigraphique des Pyrénées Occidentales (Arudy). Arudy.Pau.

MANGAS, J.; RODRÍGUEZ, A.; FRANCISCO, I. \& MARTÍN, E.

2006 Canteras aborígenes de molinos de mano de la isla de Gran Canaria (España): Caracterización petrológica de tobas de lapilli. Geo-Termas 10, 1301-1304. 
MARREIROS, J.M., GIBAJA, J.F. \& BICHO N. F. eds,

2015 Use-Wear and Residue Analysis in Archaeology. Springer.

MARTíN, E.; RODRíGUEZ, A. C.; VELASCO, J.; ALBERTO, V. \& MORALES, J.

2001 Montaña de Hogarzales: un centro de producción de obsidiana, un lugar para la reproducción social. Tabona 10,127-166.

MILLARES, $A$.

1880 El Cenobio de Valerón. Revista del Museo Canario 1(1).

\section{MONTAGNE, R.}

1929 Un magasin collectif de l'Anti Atlas L'agadir des Ikounka. Hésperis IX.

MORALES, J., RODRÍGUEZ, A., GONZÁLEZ, M.C., MARTíN, E., HENRÍQUEZ, P. \& DEL PINO, M.

2014 The archaeobotany of long-term crop storage in northwest African communal granaries: a case study from pre-Hispanic Gran Canaria (cal. AD 1000-1500). Vegetation History and Archaeobotany. DOI: 101007/s00334-014-0444-4.

\section{MORALES, J. \& RODRÍGUEZ, A.C}

2014 Gran Canaria C 14. Los antiguos canarios y el carbono 14. Boletín electrónico de Patrimonio Histórico, 2. Cabildo de Gran Canaria.

\section{MORALES PADRÓN, F.}

2009 Canarias crónicas de su conquista. Transcripción, estudio y notas. Cabildo Insular de Gran Canaria.

NARANJO, Y.

2013 Estudio de los materiales de molienda y otro utillaje pesado en las Islas Canarias en la etapa preeuropea. Un estudio preliminar dedicado a la Gran Canaria preeuropea. Trabajo Fin de Máster. Universidad de Las Palmas de Gran Canaria.

\section{NARANJO, Y. \& RODRÍGUEZ, A.C.}

2014 Propuesta de clasificación de los instrumentos de molienda y otro utillaje lítico no tallado de los antiguos canarios. Hacia una tipología morfo-funcional. XXI Coloquio de Historia Canario-Americana. Las Palmas de Gran Canaria (en prensa).

\section{ONRUBIA, J.}

1986 Sellos y marcas de propiedad de graneros fortificados del Aurés (Argelia). Consideraciones etnoarqueológicas en torno a las presuntas correlaciones norteafricanas de las pintaderas de Gran Canaria. Trabajos de Prehistoria 43, 281-307.

1995 Magansins de falaise préhispaniques de la Grande Canarie. Viabilité et conditions de formulation d'une Hypothese de référence etchnoarchaeologique." Etno-archéologie méditerrannéenne CCV-54, no. Magasins de falaise préhispaniques, 159-80.

2003 La Isla de los Guanartemes. Territorio, sociedad y poder en la Gran Canaria indígena (siglos XIV-XV). Ediciones Cabildo de Gran Canaria. Las Palmas de Gran Canaria.
PÉREZ, F.J.

2000 Historia Geológica de Gran Canaria. I Jornadas Canarias de Geología. Las Palmas de Gran Canaria, 5-8 abril

PROCOPIU, $\mathrm{H}$.

2001 Les meules a va-et-vient minoennes: histoire des choix techniques, in Texvou. Techniques et sociétés en Méditerranée. 229-39. Maisonneuve \& Larose-MMSH.

RAMÍREZ, M.

2000 Aproximación historiográfica a la investigación Arqueológica en Canarias: La Comisaría provincial de excavaciones arqueológicas de Las Palmas (1940-1969). Tercer Congreso de Arqueología Peninsular. ADECAP.

RODRÍGUEZ, A. C.

1993a La industria lítica de la Isla de La Palma. "Cuevas de San Juan": un modelo de referencia. Tesis doctoral (1990). Publicada en microfichas. Universidad de La Laguna.

1993b Analyse fonctionnelle des outillages lithiques en basalte de l'île de La Palma (îles Canaries). Prémiers résultats., in OTTE, M. (ed.). Le Geste Retrouvé. 295-301. Eraul 50.

1998a Traceología de las obsidianas canarias. Resultados experimentales. El Museo Canario LIII, 21-58.

1998b Primeras experiencias de análisis funcional en los instrumentos de basalto tallado de Canarias. El ejemplo de material prehistórico de la isla de La Palma. Vegueta 3, 29-46.

2009a La gestión de los recursos líticos en el yacimiento de La Cerera, en GONZÁLEZ QUINTERO, P. y MORENO, M (2009). El yacimiento arqueológico de La Cerera: un modelo de ocupación en la isla de Gran Canaria. Cabildo de Gran Canaria. Las Palmas de Gran Canaria. Cuadernos de Patrimonio 9.

2009b Use-wear analysis on volcanic grainy rocks: problems and perspectives. The exemple of Canary Island. Material, en ARAÚJO, M. DE \& CLEMENTE, I. (eds.). Recent Functional Studies on non flint stone tools: Methodological improvements and Archaeological Inferences. 1-10. Disponible en: http://www.workshop-traceologia-lisboa 2008.com.

2010 Piedra a piedra: la explotación de minas y canteras en la Gran Canaria preeuropea, en SUÁREZ, V., TRUJILLO, G.A. Y DOMíNGUEZ, O. (eds.). La cultura de la piedra. VII Jornadas de patrimonio Cultural de Teror. 18-41. Anroart Ediciones.

\section{RODRíGUEZ, A. C. \& BARROSO, V.}

2001 Labrar la piedra para moler el grano. La explotación prehistórica de las canteras de molinos de toba en la isla de Gran Canaria. El Pajar 10, 4-9.

RODRÍGUEZ, A.C. \& FRANCISCO, M.I.

2012 Estudio de los picos tallados de la época preeuropea de Gran Canaria. Un ejemplo de especialización en el trabajo a partir de las evidencias recuperadas en la cantera de molinos de Montaña Quemada. Complutum 23(1), 77-97.

\section{RODRÍGUEZ, A. C. \& GALINDO, A.}

2004 El aprovechamiento de los recursos abióticos en un poblado costero de la isla de Gran Canaria. Las industrias líticas del yacimiento de El Burrero (Ingenio). Tabona 13, 143-165. 
RODRÍGUEZ, A.C.; GONZÁLEZ, M.C.; MANGAS, J.; MARTÍN, E. \& BUXEDA, J.

2007b La explotación de los recursos líticos en la isla de Gran Canaria. Hacia la reconstrucción de las relaciones sociales de producción en época preeuropea y colonial. III Reunión de trabajo de la explotación de Recursos Abióticos (G. Martínez, A. Morgado, J. Afonso, eds). 367-391.

RODRÍGuEZ, A. C., JIMÉNEZ MEINA, A. M., ZAMORA, J. M. \& MANGAS, J.

2006a El empleo de cantos rodados en la elaboración de la loza tradicional de la isla de Gran Canaria, implicaciones etnoarqueológicas. Trebals d'Etnoarqueologia 6, 209-225.

RODRíGUEZ, A. C., JIMÉNEZ\& A. M., ZAMORA

2006b El instrumental lítico en el trabajo de la loza tradicional: apuntes etnoarqueológicos. Actas del XVI Coloquio de Historia Canario Americana, 419-36. Ediciones Cabildo de Gran Canaria. Las Palmas de Gran Canaria.
RODRÍGUEZ, A.C.; MANGAS, J.; BUXEDA , J; MARTíN, E \& FRANCISCO, M.I.

2010 La explotación de las canteras de molinos de mano rotatorios en la Gran Canaria preeuropea, en DOMíNGUEZBELLA, S. et al. (eds.). Minerales y rocas en las sociedades de la prehistoria. Universidad de Cádiz.

RODRÍGUEZ, A. C. \& MARTíN, E.

2007a Las canteras de molinos de mano de Gran Canaria. Anatomía de unos centros de producción singulares. Tabona 15, 115-141.

WÖLFEL, D.J.

1954 El "cenobio" de Valerón. Revista de Historia XX 105$108,83-84$ 